\title{
SEVERE TACTUAL AS WELL AS VISUAL MEMORY DEFICITS FOLLOW COMBINED REMOVAL OF THE AMYGDALA AND HIPPOCAMPUS IN MONKEYS ${ }^{1}$
}

\author{
ELISABETH A. MURRAY ${ }^{2}$ AND MORTIMER MISHKIN \\ Laboratory of Neuropsychology, National Institute of Mental Health, Bethesda, Maryland 20205 \\ Received February 14, 1983; Revised May 9, 1984; Accepted May 16, 1984
}

\begin{abstract}
To determine whether medial temporal limbic structures are essential for memory in more than one modality, we trained monkeys preoperatively on both visual and tactual versions of a sensory memory task and then retested them after they had been given bilateral ablations of either the amygdaloid complex, the hippocampal formation, or both. Monkeys with the combined ablations were severely impaired in both modalities. By contrast, the amygdalectomized monkeys were only moderately impaired in the two modalities, while the hippocampectomized monkeys were impaired in neither. Further examination revealed that the source of the impairment in the monkeys with amygdalectomy alone, unlike that in the animals with combined lesions, was the small size of the pool from which the test objects were drawn. The latter result suggests that, whereas the sensory memory impairment following the combined lesions is basically a recognition loss, the more selective impairment following amygdalectomy alone reflects special difficulty in determiing whether a recognized object was presented recently. By demonstrating that the profound sensory memory impairment that follows combined ablation of the amygdala and hippocampus extends beyond a single modality, the present results strengthen the proposals that (i) these two structures are important for sensory memory in all modalities and (ii) the multimodal or global amnesia observed in patients with medial temporal lobe damage is likewise due to combined amygdaloid and hippocampal lesions.
\end{abstract}

Bilateral medial temporal lobe damage in humans results in a profound anterograde amnesia, a condition characterized by a severely deficient memory for stimuli and events experienced subsequent to the damage. The amnesia is also referred to as "global" in that it extends to many types of information derived from all sensory modalities (Corkin, 1965; Milner, 1972). Although the neuropathological evidence has been interpreted as indicating that this temporal lobe syndrome is due to hippocampal damage (Scoville and Milner, 1957; Penfield and Milner, 1958; Penfield and Mathieson, 1974), experimental studies in nonhuman primates have suggested the alternative possibility that the syndrome results from combined damage to the hippocampus and amygdala. The latter proposal is based on a finding in monkeys that, whereas ablation of the hippocampus or amygdala alone resulted in only mild deficits on visual memory tasks, combined ablation of these two structures yielded extremely severe deficits (Mishkin, 1978; Mishkin et

\footnotetext{
${ }^{1}$ This work was supported in part by National Institutes of Health Postdoctoral Fellowship NS 06276 to E. A. M. Preliminary reports of this work have appeared elsewhere (Murray and Mishkin, 1981, 1983a). We thank Mr. Linton Stokes, Mr. Leon Dorsey, Mr. Louis Cali, and Ms. Leslie Risin for their valuable technical support, Dr. David Gaffan for his suggestions on test design, and Dr. Karen Pettigrew for her help with the statistical analyses.

${ }^{2}$ To whom correspondence should be addressed, at Laboratory of Neuropsychology, Building 9, Room 1N-107, National Institute of Mental Health, Bethesda, MD 20205.
}

al., 1982). In the present experiment we attempted both to corroborate that finding and to determine whether the same results would be obtained in a modality other than vision. To this end, monkeys with amygdalectomy, hippocampectomy, or the two removals combined were compared on tactual as well as visual versions of a sensory memory task. If the combined but not the separate lesions were to yield a severe memory impairment in both modalities, then the results would reinforce the suggestion not only that damage to these structures yields a global amnesia (Mishkin, 1978; Mishkin et al., 1982) but also that the amygdala and hippocampus are indeed the critical structures for memory in both monkeys and humans.

\section{Materials and Methods}

\section{Subjects}

The subjects were 10 cynomolgus monkeys (Macaca fascicularis) and 1 rhesus monkey (Macaca mulatta), all experimentally naive, ranging in weight from 3.2 to $5.0 \mathrm{~kg}$ at the time of surgery. All but one of the animals were males. Monkeys were maintained on a diet of monkey chow supplemented with fruit and vitamins plus iron. Water was always available.

\section{Apparatus and materials}

The monkeys were trained in a Wisconsin General Test Apparatus (WGTA) in a darkened room lined with sound-attenuating tiles. Additional sound masking was provided by a white noise generator. For visual testing, the test compartment of the WGTA was illuminated with two 60-W incandescent bulbs. For tactual testing, these incandes- 
cent bulbs were unlit, except in the initial phase of preoperative training, during which they were first fully lit and then progressively dimmed by use of a variable resistor. The animal compartment of the WGTA was always unlit. The animals' behavior in the dark was monitored on a video screen linked to an infrared camera which, together with an infrared light source, was mounted over the test compartment. Light was prevented from leaking into the test compartment during tactile testing by the following measures. During the testing session a black, light-tight shade was fastened to the back of the WGTA. Also, the video monitor was observed through a small slit $(2 \times 10 \mathrm{~cm})$ in a viewing tube lined with light-tight cloth. In addition, the one-way vision screen through which the animals' behavior in the light was normally observed was covered so that any small amount of light emanating from the end of the viewing tube could not enter the test compartment. Finally, the spaces surrounding the WGTA doors were lined with thick black foam rubber.

The test tray was black and contained a row of three food wells 15 $\mathrm{cm}$ apart, center to center. Light-emitting diodes (LEDs), recessed in the test tray $4.5 \mathrm{~cm}$ in front of each well, were used to signal the position of the objects during tactual testing. The LEDs did not provide sufficient light for visual inspection or choice, as evidenced by the following: (i) having first learned the task under normal illumination, all monkeys underwent a period of training in dim light during which they performed at or near chance levels; (ii) the animals did not achieve criterion in the dark until they were observed to compare the objects tactually before making a choice; and (iii) neither of two dark-adapted human observers, viewing the testing area under conditions of darkness identical to those used with the monkeys, was able to detect any of the objects visually.

During the preoperative phase of testing, monkeys were trained with a fixed set of 40 visually and tactually distinctive objects that differed widely in color, size, shape, texture, and compressibility. Each object was mounted on a cork, $44 \mathrm{~mm}$ top diameter $\times 15 \mathrm{~mm}$ high, that fit snugly into the wells of the testing board (cf. Jarvis and Ettlinger, 1977). This forced the monkeys to grasp and lift and, thus, palpate the objects in order to obtain their reward.

\section{Preoperative training}

Stage 1: Visual learning. The monkeys were first trained to remove a gray plaque, placed over one of the three food wells randomly, in order to uncover a reward consisting of a small banana pellet (P. J. Noyes Co., $300 \mathrm{mg}$ ). During this adaptation period the spontaneous hand preferences of the monkeys were noted and, then, as a means of ensuring that all tactile comparisons would be intramanual, the monkeys were trained to use their preferred hand only. The experimenter accomplished this by quickly lowering the opaque screen between the animal and test compartments whenever the animal attempted either to displace the plaque or to obtain a reward with the nonpreferred hand. When the animals had learned to respond with the preferred hand consistently, they were trained on delayed nonmatching-to-sample (DNMS) in the light with the set of 40 objects. Early in training, the cork-mounted objects were set in the wells at an angle so that the animals could displace them easily. As training progressed, the objects were inserted more firmly. In the first part of each trial, the animal was confronted with a sample object overlying the baited central well of the test tray, which the animal removed from the well in order to obtain the reward. 'Ten seconds later, the animal was confronted with the sample object and another object from the set, now overlying the lateral wells of the test tray. In this choice test, the sample was unbaited, and the animal was required to remove the other object in order to uncover and obtain a second reward. Following a 30-sec intertrial interval, this same trial sequence was repeated with another pair of objects, and so on, for 20 trials per session. During both the withintrial delay periods and the intertrial intervals, the animals' view of the test compartment was blocked by the opaque screen. Each of the 40 objects appeared in only one of the 20 daily trials, and the objects were re-paired randomly each day. Also, the location of the correct object during the choice test (left or right side) was varied in a balanced order. The monkeys were trained on this initial task by the noncorrection procedure to the criterion of 90 correct responses in 100 trials.

Stage 2: Tactile learning. After they had attained criterion in stage 1 , the monkeys were continued on DNMS with the same set of 40 objects as before, but now the light-dimming phase of training was introduced and a correction procedure was initiated. During this stage, the animals were kept in the WGTA for 15 to 30 min of dark adaptation before testing was begun. Light levels in the test compartment were lowered on successive blocks of trials according to a modified titration schedule in which initially large steps in light reduction were followed by smaller steps. If an animal achieved greater than $75 \%$ correct responses in a block of 10 trials, then the light level was reduced one step. If an animal achieved less than $75 \%$ correct responses, then the light level remained stable, but for no more than 2 days, after which it was lowered one step irrespective of score. In this way, the light level was reduced from 0.95 foot-lamberts (the normal light level in the test compartment) to 0.0 foot-lambert. The correction procedure, which was continued throughout tactual testing, consisted of one or more representations of the entire trial sequence (sample presentation plus choice test) following an error until the animal made the correct choice. In this stage and the next one, the central LED was lit during the sample presentation, whereas the two lateral LEDs were lit during the choice test. Once the animals reached the point of working in complete darkness, training was continued until they mastered the tactual DNMS to the same criterion as in the light (see "Stage 1: Visual learning").

Stage 3: Tactile performance. After attaining criterion in total darkness, the animals were given a performance test in which the delay between the sample presentation and test was increased from $10 \mathrm{sec}$ to 30,60 , and, finally, $120 \mathrm{sec}$, in blocks of 100 trials (i.e., five daily sessions) at each delay. During this stage, a record was kept not only of correct and incorrect choices and correction trials, but also of which objects were paired for each trial and whether or not the animal compared the objects, i.e. touched both, before making a choice. On completion of stage 3 , the animals were divided into three surgical groups that were balanced for preoperative learning and performance scores.

\section{Surgery}

Four animals received bilateral hippocampectomy $(\mathrm{H})$, five animals received bilateral amygdalectomy $(\mathrm{A})$, and two received both lesions combined $(\mathrm{AH})$. One animal that initially received a hippocampectomy (H1) later received an amygdalectomy (AH2), thereby increasing to three the number of animals in the combined lesion group. Monkeys were anesthesized with an initial dose of ketamine hydrochloride (10 $\mathrm{mg} / \mathrm{kg}$ ) followed by Nembutal, which was administered intravenously as required (approximately 20 to $30 \mathrm{mg} / \mathrm{kg}$ ). All animals received an intravenous drip of a solution of $5 \%$ dextrose and 0.45 sodium chloride and were monitored for heart rate, respiration rate, and temperature. The bilateral surgical ablations, carried out with the aid of an operating microscope, were performed aseptically in a single stage, with the one exception noted above. After the removals were completed, the dura mater was sutured and the scalp was closed in anatomical layers. All animals received an antibiotic as a prophylactic measure.

The hippocampal formation, consisting of the dentate gyrus, hippocampus proper, and all the subfields of the subiculum (Swanson and Cowan, 1975), was removed via a ventral temporal approach. The occipitotemporal convexity above the labyrinth was elevated to expose the occipitotemporal sulcus. Tissue just medial to the anterior 8 to 10 $\mathrm{mm}$ of the sulcus was entered with a small-gauge sucker until the ventricle was opened. The hippocampal formation was then retracted from the roof of the ventricle, followed anteriorly and posteriorly, and aspirated. The boundaries of the hippocampal ablation were the occipitotemporal sulcus ventrolaterally, the roof of the ventricle dorsally, the brainstem medially, and the amygdaloid complex anteriorly. The removal thus included not only the hippocampal formation but also the parahippocampal gyrus and the posterior part of the entorhinal cortex. When the lesion was completed, the posterior surface of the amygdala was exposed and clearly visible at the rostral end of the ventricle.

The amygdaloid complex was removed via an orbital frontal approach. The frontotemporal junction above the orbit was elevated slightly and the tissue just medial to the anterior tip of the rhinal sulcus was entered with the sucker. The amygdala was then removed by aspiration, the boundaries of the ablation consisting of the rhinal sulcus ventrolaterally, the white matter of the temporal stem laterally, and the hippocampus posteriorly. The lesion thus included not only the amygdaloid complex itself but also temporal piriform cortex as well as the anterior part of the entorhinal cortex, both of which are located medial and ventral to the amygdala. When the lesion was completed, the rostral end of the hippocampal formation (pes hippocampus) was exposed and clearly visible in the ventricle. 
The amygdaloid plus hippocampal removal was the combination of the two ablations, with the amygdalectomy preceding the hippocampectomy in each of the two animals given one-stage removals (AH1 and $\mathrm{AH} 3$ ), but with the order reversed in the animal given the twostage removal (AH2). The possible importance of order of lesions for successful removal of the amygdala is noted below (see "Histology").

\section{Postoperative training}

Tactual testing. Postoperative training on the tactual DNMS with 10-sec delay between sample presentation and test was initiated 10 to 14 days after surgery. Animals that could not reattain criterion within 1000 trials were allowed up to 500 additional trials with double presentations of the sample object, first with food reward and then, $10 \mathrm{sec}$ later, without reward. This procedure was adopted on the assumption that maintenance of the rule that the sample object was positive (or baited) on its first presentation only would facilitate acquisition of the nonmatching principle. When the animals had reattained the criterion of 90 correct responses in 100 trials or had reached the retraining limit, they were again given a performance test with the longer delays (i.e., five daily sessions each with delays of 30,60 , and $120 \mathrm{sec}$ intervening between sample presentation and test). Animals given double sample presentation during relearning continued to receive double sample presentation during performance testing. Otherwise, all procedures for the tactual memory task were identical to those that were in effect during stage 3 of preoperative training.

Visual testing. Following completion of tactual testing, all animals except AHl were tested on DNMS in the light with the same set of objects as before (set A), so that performance in both visual and tactual memory could be directly compared. To ensure that a selection was made visually, a response was scored the moment either object was first touched (i.e., the animals were not allowed to compare objects tactually before making their choice). The monkeys were trained in the light with delays of $10,30,60$, and $120 \mathrm{sec}$, in successive blocks of 100 trials (i.e., five daily sessions) at each delay.

Visual testing: Effect of set size. The amygdalectomized monkeys in the present study were found to perform more poorly on the visual memory task than did those in the earlier study (Mishkin, 1978). In the earlier study, however, the animals had been trained with a large set of objects that yielded novel pairs not only within sessions, as here, but also across sessions. In order to examine the effects on performance of the size of the object set, four amygdalectomized and three hippocampectomized animals were tested on visual DNMS with two additional sets, in the following order: a large set of 200 objects, and a second small set (set B) of 40 objects. With small set B, as with the original small set $A$, each object appeared in only one trial each day, whereas with the larger set, each object appeared in only one trial each week. All of the objects in the second and third sets, like those in the first set, were mounted on corks and also differed widely from each other in color, shape, texture, and size. For these two sets of objects, just as with the original set, the monkeys were trained in the light with delays of $10,30,60$, and 120 sec, in successive blocks of 100 trials (i.e., five daily sessions) at each delay.

\section{Histology}

Following completion of behavioral testing all animals were perfused intracardially with saline and then $10 \%$ formalin. The brains were embedded in celloidin and sectioned in the coronal plane at $25 \mu \mathrm{m}$, and every 10 th section was stained with thionin.

All four cases in the hippocampectomized group had complete, bilateral removals of the hippocampal formation. In all of these animals the expected gliosis in the fornix and in the medial nucleus of the mamillary bodies was evident bilaterally. Coronal sections through the lesions and surface views for two representative cases $(\mathrm{H} 2$ and $\mathrm{H} 3)$ are illustrated in Figures 1 to 3, and surface views only are shown for a third case $(\mathrm{H} 4)$ in Figure 7. The lesion in case $\mathrm{H} 1$, to which an amygdalectomy was later added, is illustrated in Figure 6 (see case $\mathrm{AH} 2$ ). As for unintended damage, case $\mathrm{H} 1$ had none, and cases $\mathrm{H} 2$ and H3 sustained only a small amount bilaterally, specifically to the inferior temporal cortex, where this tissue had been raised to gain access to the hippocampus. As a consequence of infarction, however, the damage on one side in case H2 extended rostrally from the area that had been elevated to include tissue near the caudal tip of the anterior middle temporal sulcus (see Figs. 1 and 3). Finally, case $\mathrm{H} 4$ had damage to almost the entire inferior temporal convexity on the right (see Fig. 7), apparently as a result of postoperative infection of the surgical wound. The infection had been noted and treated with antibiotics and had cleared up within 10 days of surgery; thus the animal was retrained in the normal manner. However, bacterial remains were visible on the coronal sections at the site of the tissue damage, which consisted of moderate to marked cell loss throughout the middle and inferior temporal gyri and the adjacent lower bank of the superior temporal sulcus. On the left, there was slight damage to inferior temporal cortex like that in cases $\mathrm{H} 2$ and $\mathrm{H} 3$, at the level at which this cortex had been elevated during surgery. In none of these cases was there detectable damage to the amygdaloid complex (see Figs. 2 and 3).

Histology is available for only four of the five animals that received an amygdalectomy, since the fifth case, A5, is still undergoing testing in a follow-up experiment. All four cases examined had complete removal of the amygdaloid complex, resulting in marked gliosis bilaterally within the stria terminalis. Coronal sections and surface reconstructions for two representative cases (A1 and A2) are illustrated in Figures 4 and 5, while surface views only are shown for the others in Figure 7. In addition to the intended removal, there was damage to the tail of the caudate nucleus on the right in case $\mathrm{A} 1$ and bilaterally in case A2. Case A3, although receiving no apparent unintended damage (see Fig. 7), was found to have enlarged inferior and posterior horns of the lateral ventricles. This hydrocephalus, which had been noted at surgery when the ventricles behind the amygdalae were opened, was associated with a bilaterally shrunken and medially displaced hippocampal formation as well as a patchy cell loss in the anterior insular cortex and in the ventral bank of the lateral sulcus. Finally, case A4 received moderate bilateral damage to the inferior frontal convexity, consisting of cell loss in the superficial layers only, presumably due to the lifting of this convexity during surgery in order to gain access to the amygdala (see Fig. 7). Less extensive damage to this same region was found in cases A1 and A2, as shown in Figure 4. In none of these cases was there detectable damage to the hippocampal formation.

Two of the three animals in the group with combined amygdaloid and hippocampal lesions (AH1 and $\mathrm{AH} 3$ ) sustained complete removals. In case AH2 (initially $\mathrm{H} 1$ ), however, in which the amygdalectomy was added in a second-stage operation, there was bilaterally symmetrical sparing of the posterodorsal amygdala, including the cortical and medial nuclei as well as the posterodorsal parts of the lateral and lateral basal nuclei. This sparing was probably due to the absence of the landmark normally provided by the intact spherical tip of the hippocampal formation at the posterior boundary of the ablation, a landmark that was present in all other animals that reccived amygdalectomy either alone or in combination with hippocampectomy. With the landmark gone, the height of the posterodorsal amygdala was difficult to judge and was underestimated. Nevertheless, in this animal, as in the others with combined lesions, gliosis was evident bilaterally in the stria terminalis as well as in the fornix and medial nucleus of the mamillary bodies. Coronal sections through the lesions and surface reconstructions for two of the cases (AH2 and $\mathrm{AH} 3$ ) are illustrated in Figure 6, and a surface reconstruction from the remaining animal (AH1) is shown in Figure 7. The largest amount of unintended damage was sustained by case $\mathrm{AH} 1$ (see Fig. 7), the single rhesus monkey in the study and the only one that was not tested for visual memory. This animal had an infarction of the striate and prestriate cortex along the calcarine fissure in the left hemisphere, presumably as a result of occlusion at surgery of the calcarine branch of the posterior cerebral artery (Zeal and Rhoton, 1978). The damage extended from the posterior limit of the intended ablation to the occipital pole but was confined to the ventromedial surface of the hemisphere. In addition to the large infarct on the left, there was a smaller infarct involving the tail of the caudate nucleus and adjacent optic radiations on the right. Finally, this animal received slight superficial inferior frontal damage, as in cases Al and $\mathrm{A} 2$, and bilateral damage to the inferior temporal cortex, primarily where this cortex had been raised in order to gain access to the hippocampus. Case $\mathrm{AH} 2$, which had the two-stage lesion and consequent sparing of the posterodorsal amygdala, sustained little or no unintended damage. Finally, in case $\mathrm{AH} 3$, as in $\mathrm{AH} 1$, there was destruction of the tail of the caudate nucleus and adjacent optic radiations on the right. Based on the resulting degeneration of the posterior portion of the right dLGN, the radiation damage probably produced a left foveal field defect, although this deficit was not evident on gross neurological examination. In addition, case AH3 sustained minor bilateral inferior temporal damage, again at the level at which this cortex had been elevated. 

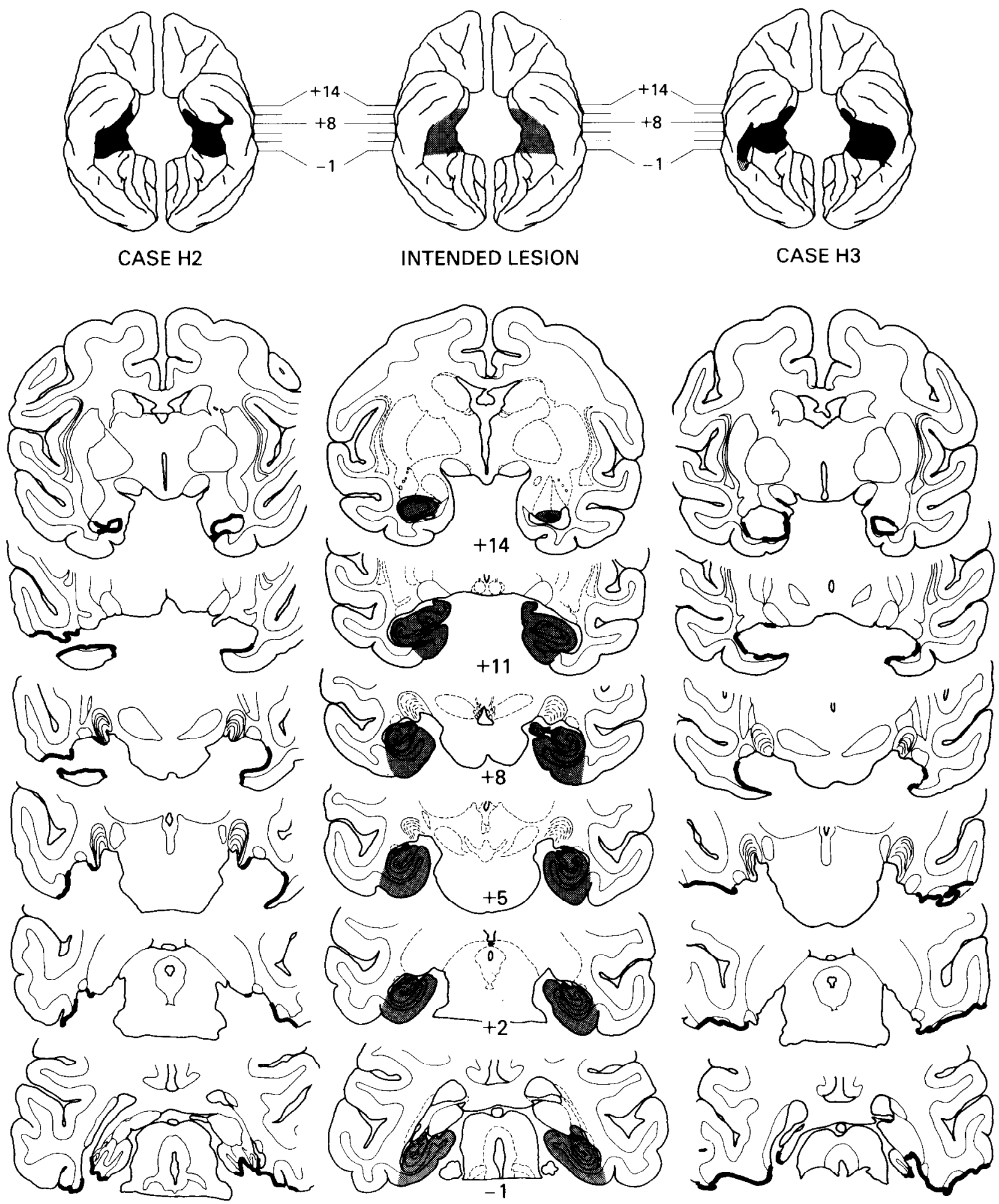

Figure 1. Hippocampal ablations. Shaded areas in the central column indicate intended lesion on ventral surface view of the brain (top) and on coronal sections (below). Lateral columns show ventral surface reconstructions of actual lesions (black area) in two cases (top) and coronal sections through these lesions (heavy black lines) at the same levels as the sections shown in the central column (below). Oblique hatching (case $H 3, t o p)$ denotes region of partial cell loss. Numbers indicate approximate distance in millimeters from the interaural plane (0). Note unintended damage to anterior temporal cortex on the left in case $\mathrm{H} 2$ (levels +8 and +11 ) and to posterior temporal cortex bilaterally in case $H 3$ (levels +5 , +2 , and -1 ). 

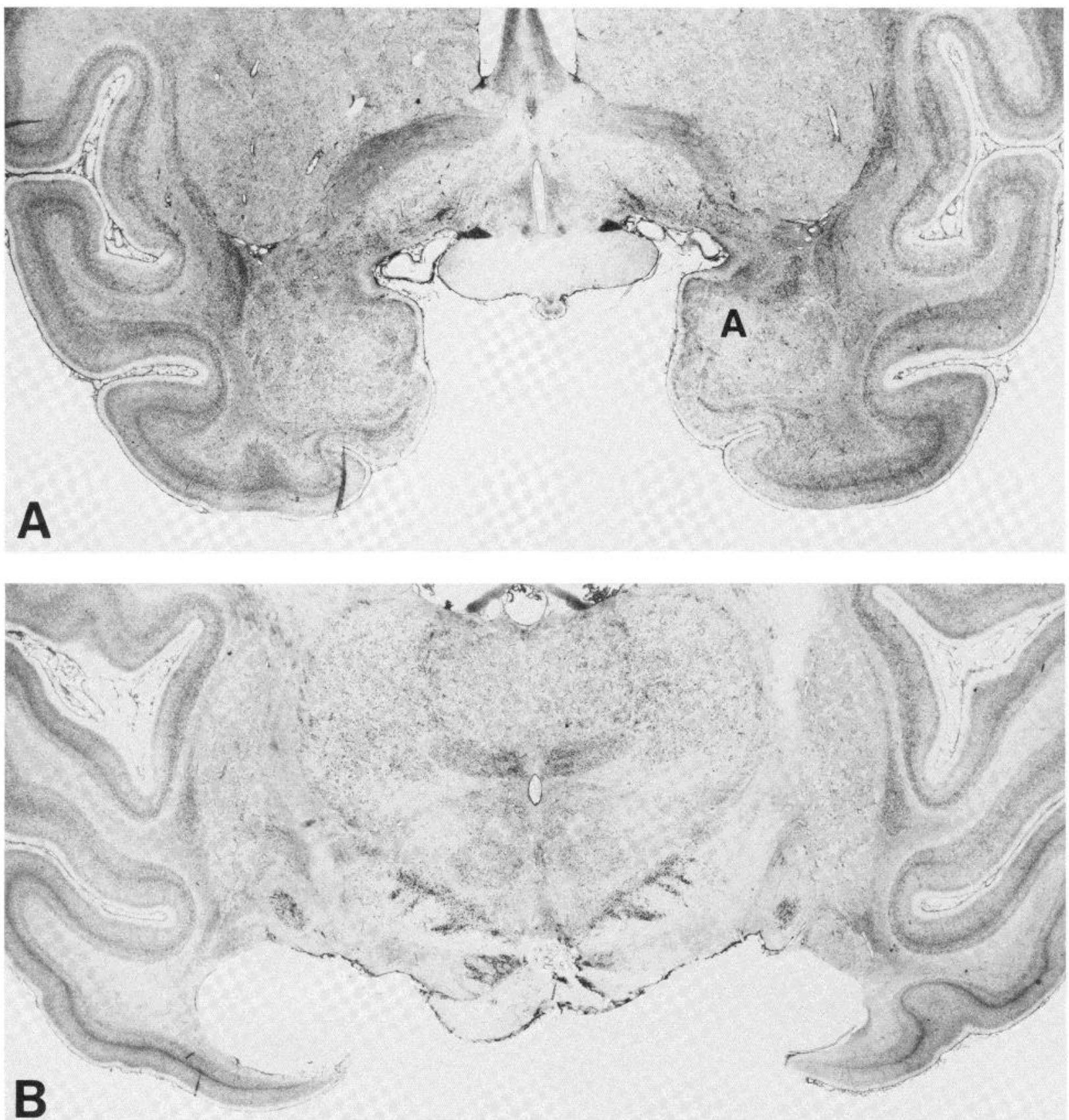

Figure 2. Photomicrographs of Nissl-stained coronal sections from case H3. A, Section through the intact amygdaloid complex (A) at approximately +17 . $B$, Section through the hippocampal lesion, at approximately +9 . Compare with Figure 1 (right-hand column). Contrast with Figure 5, which shows sections at similar levels, but from an animal with amygdalectomy.

\section{Statistics}

Parametric tests (analysis of variance with repeated measures on one factor, Newman-Keuls test, and the $t$ test) and nonparametric tests (Mann-Whitney $U$ test) were carried out where appropriate (Siegel, 1956; Winer, 1971). The use of Bonnferroni tables (Miller, 1980), which take into account the number of animals in the group $(n)$, the number of comparisons made $(k)$, and the degrees of freedom $(v)$, allowed comparison between groups at specific delays.

\section{Results}

\section{Preoperative learning and performance}

Preoperatively, the animals averaged 264 trials (range, 180 to 320 ) and 65 errors (range, 30 to 95 ) for original learning of
DNMS in the light (stage 1) and an additional 384 trials (range, 280 to 480 ) and 65 errors (range, 24 to 93 ) to attain criterion in the dark (stage 2). On the performance test in the dark (stage 3), the animals averaged $91 \%$ over the three longer delays (see Table I). The preoperative scores of the rhesus monkey (AH1) fell in the middle of the scores of the cynomolgus monkeys (240 trials on stage 1,400 additional trials on stage 2 , and $91.3 \%$ on stage 3 ). An analysis of variance confirmed that the three surgical groups that were formed did not differ significantly in their level of preoperative performance.

\section{General effects of the lesions}

With one exception, animals with amygdalectomy (either alone or in combination with hippocampectomy) showed the 

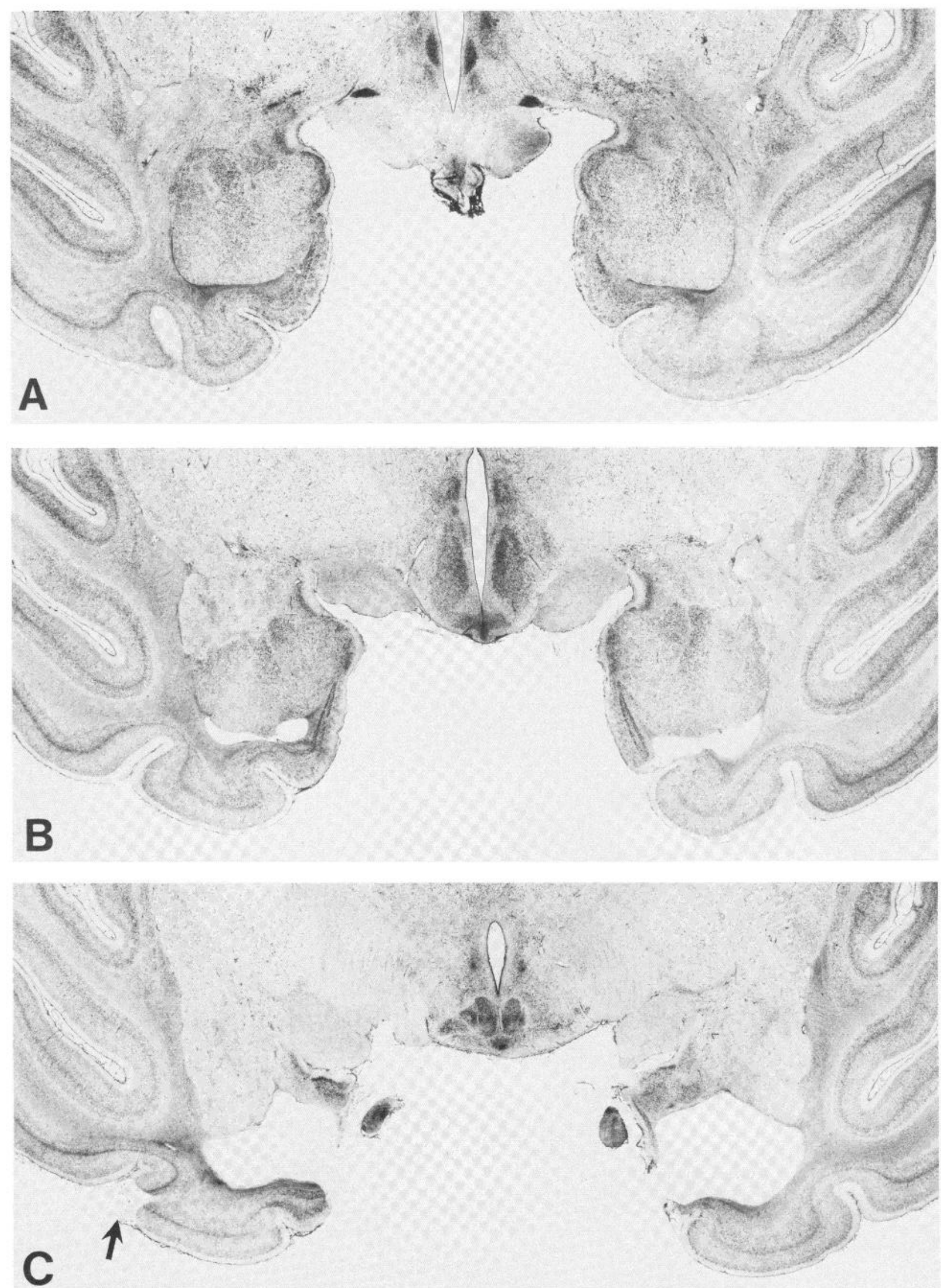

Figure 3. Photomicrographs of Nissl-stained coronal sections from case H2. A, Section through the intact amygdala, near its posterior extent, at approximately +15.5 . $B$, Section through the anterior end of the inferior horn of the lateral ventricle, at approximately +14.0 , where the rostral tip of the hippocampus was removed but overlying amygdala was spared. $C$, Section through hippocampal lesion, at approximately +12.0 , showing also the anterior limit of unintended damage to inferior temporal cortex on the left (arrow). Compare with Figure 1 (left-hand column). 
characteristic behavioral changes associated with this ablation (Weiskrantz, 1956). The changes included reduced fearfulness and indiscriminate grasping and mouthing of objects, including transient coprophagia. The one exception was the monkey with sparing of the posterodorsal amygdala (case AH2), who showed none of these signs. The amygdalectomized monkey whose lesion has not yet been histologically examined (case A5) chronically pulled objects into its cage during test sessions. Because the appropriation of objects by the monkey and their subsequent retrieval by the experimenter disrupted the monkey's relearning, strings were attached to the objects (for this animal only) so that the animal could not steal them.

By contrast to the monkeys with amygdalectomy, those with hippocampectomy alone displayed either no obvious change in behavior or appeared slightly more excited or fearful than before. One hippocampectomized animal (case $\mathrm{H} 3$ ) displayed

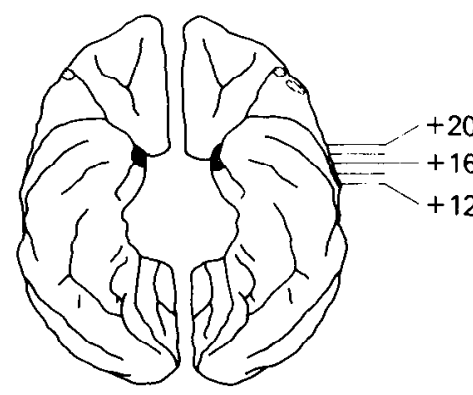

CASE A1

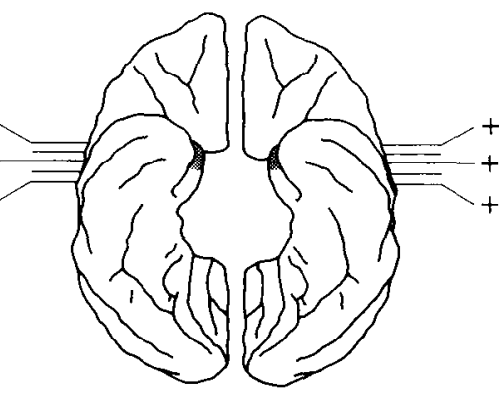

INTENDED LESION

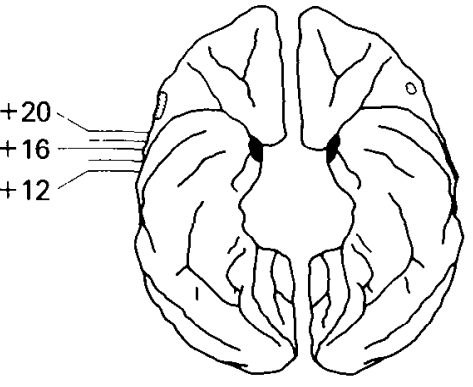

CASE A2

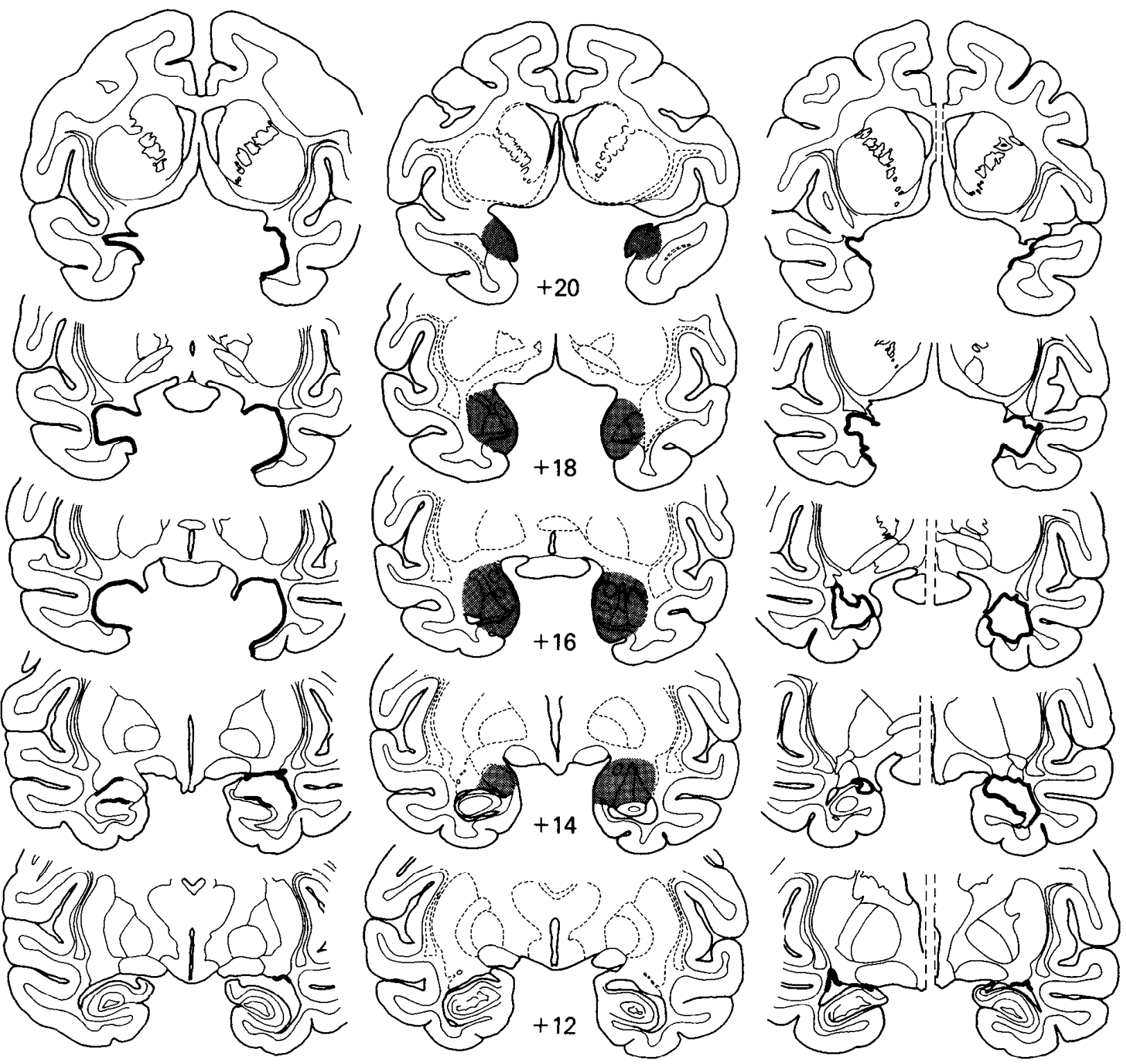

Figure 4. Amygdaloid ablations; conventions as in Figure 1. Oblique hatching on surface views denotes minute regions of partial cell loss in orbital frontal cortex. Compare with frontal damage in Figure 7, case A4. 

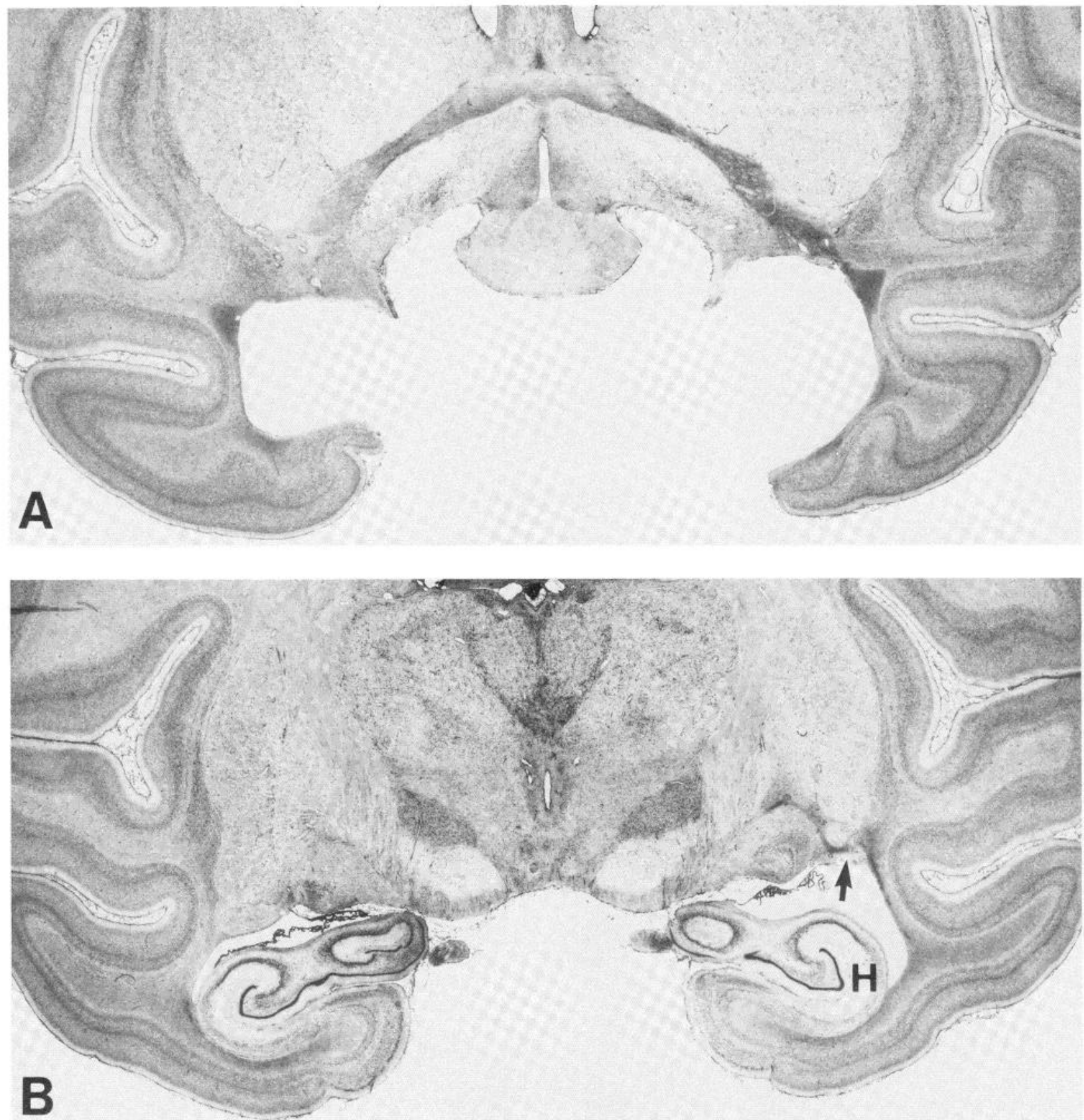

Figure 5. Photomicrographs of Nissl-stained coronal sections from case A1. $A$, Section through amygdaloid lesion at approximately +17 . $B$, Section through intact hippocampal formation $(H)$, at approximately +10 . Note unintended damage to the tail of the caudate nucleus on the right (arrow). Compare with Figure 4 (left-hand column). Contrast with Figure 2, which shows sections at similar levels, but from an animal with hippocampectomy.

mild, transient misreaching. Also, one animal with a combined lesion (case AH1) was initially clumsy when using its preoperatively trained hand, and another (case $\mathrm{AH} 3$ ) was reluctant to use its preoperatively trained hand but was readily retrained to do so. These motor problems, none of which could be correlated with visible cerebral damage, did not appear to interfere with performance on any of the tasks. It should be noted that, except for case $\mathrm{AH} 3$, all animals began using their preoperatively trained hand immediately upon tactual testing postoperatively.

\section{Tactual DNMS}

The results of the tactual testing are summarized in Table I and Figure 8. Statistical analyses revealed that the surgical treatments had a significant effect on the relearning of the tactual memory task $(F(d f 2,9)=24.05, p<0.001)$. In addition, there was a significant interaction of group and delay on the performance test $(F$ (conservative $d f 2,9)=5.63, p<0.05$ ). More detailed comparisons are given below.

Hippocampectomy alone. Monkeys with hippocampal ablations averaged only 20 trials to reattain criterion on tactual DNMS with a 10-sec delay. Furthermore, they showed little evidence of forgetting on the performance test even at the 120sec delay (see Fig. 8). Indeed, each hippocampectomized animal actually performed slightly better than it had preoperatively (see Fig. 9), although the group's postoperative average of $94 \%$ was not significantly different from its preoperative average of $91 \%$ ( $t$ test, $p>0.2$ ). 
Amygdalectomy alone. The amygdalectomized monkeys showed the widest range of scores in tactual relearning and performance, a variability that could not be ascribed to any of the deviations from the intended lesions noted under "Histol- ogy." All five of the amygdalectomized monkeys exhibited some retardation in reattaining criterion; but, whereas two relearned in under 500 trials, two others could not relearn within the training limit of 1000 trials. One of the latter animals (case A4,

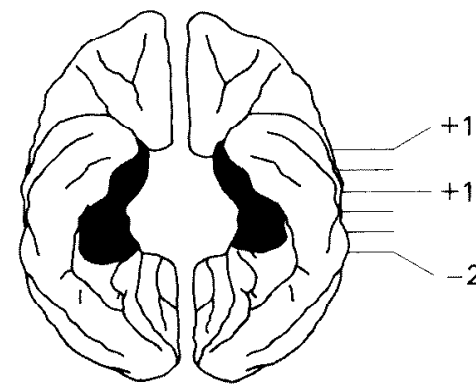

CASE AH2

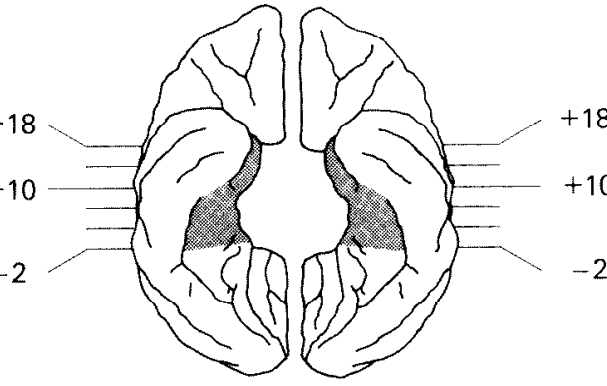

INTENDED LESION

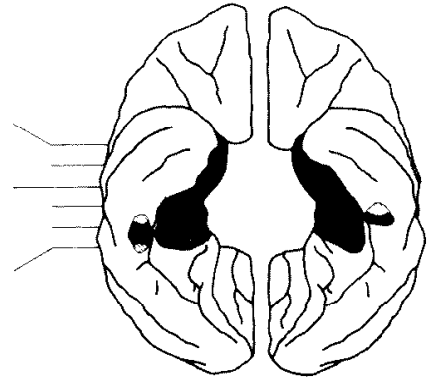

CASE AH3
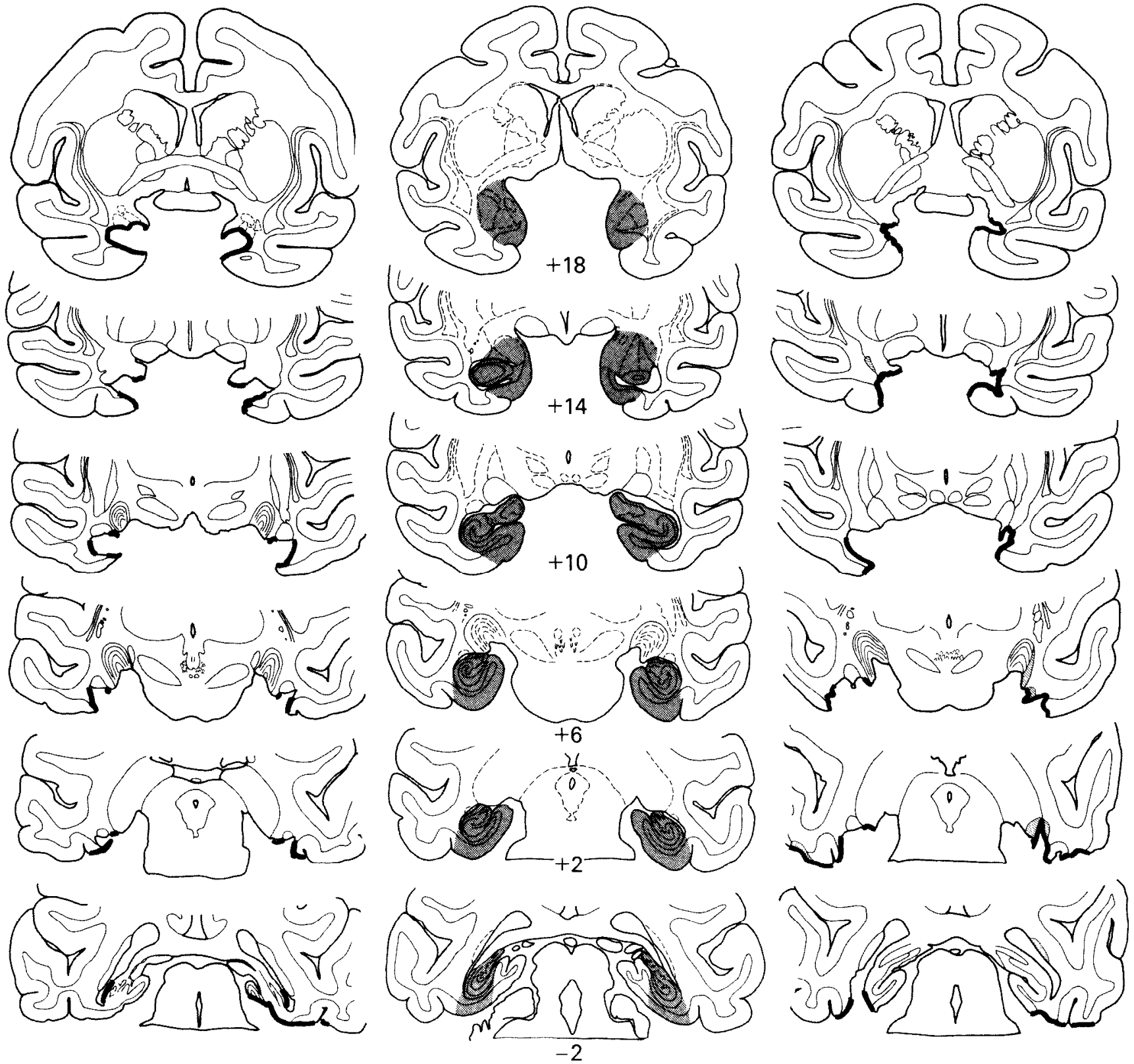

Figure 6. Combined amygdaloid and hippocampal ablations; conventions as in Figure 1. Note bilateral sparing of posterodorsal amygdala in case AH2 (level +18 ), and unintended damage in case $A H 3$ to inferior temporal cortex bilaterally (level +2 ) and to the tail of the caudate and the lateral geniculate nucleus on the right (levels +2 and +6 ). 


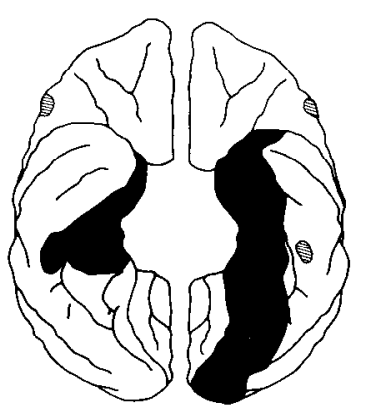

CASE AH1

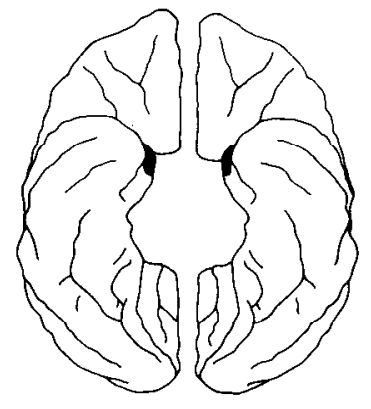

CASE A3
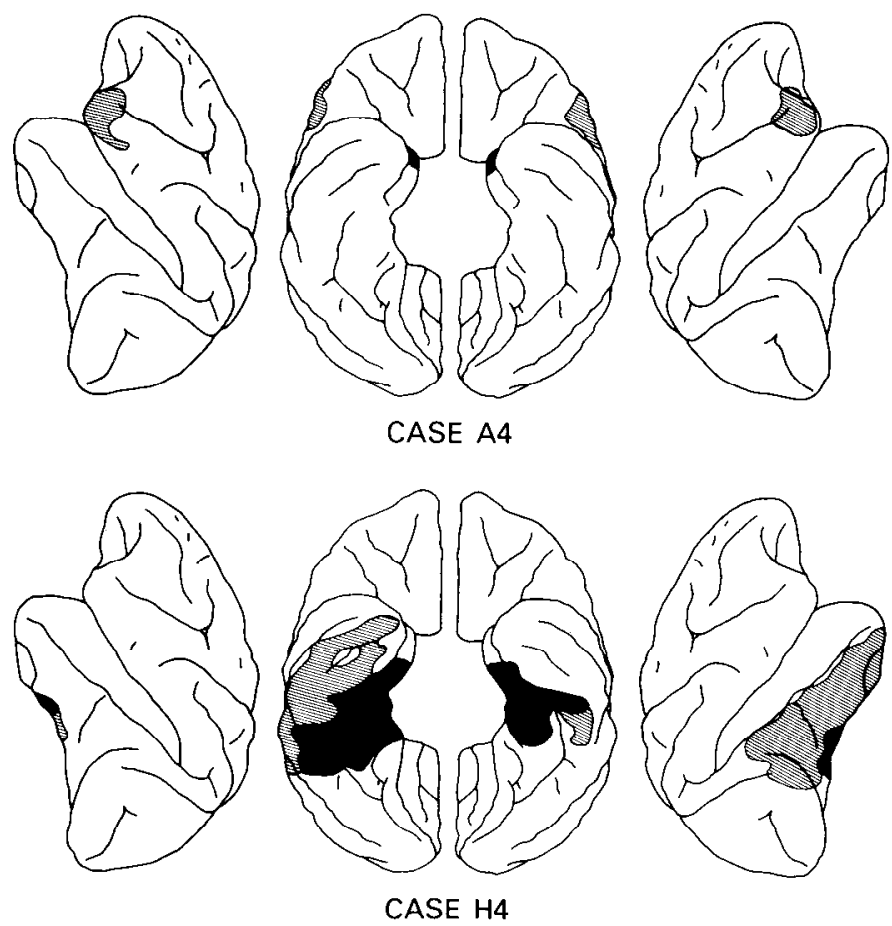

Figure 7. Lesions in cases $\mathrm{AH} 1, \mathrm{~A} 3, \mathrm{~A} 4$, and $\mathrm{H} 4$ reconstructed onto ventral or both ventral and lateral surface views of the brain. Complete cell loss is shown in black; partial cell loss is shown in oblique hatching.

with the unintended damage to the inferior frontal convexity) achieved a final score of $81 \%$ correct responses, which was deemed sufficiently high to warrant moving this animal directly to the performance test. The other animal that failed (case A1) performed less well, however, and was therefore given double sample presentation, after which it reached criterion immediately; this animal continued to receive double sample presentation with the longer delays. The average relearning score for the group, including the four animals that reached criterion and the one that did not, was 716 trials, which was significantly worse than the average score of 20 trials for the hippocampectomized group (Mann-Whitney $U$ test, $U=0, p=0.008$ ). On the performance test, the amygdalectomized monkeys were again moderately impaired. Their average score of $80 \%$ was significantly below the $94 \%$ score of the hippocampectomized monkeys (Newman-Keuls test, $p<0.01$ ) as well as their own preoperative score of $91 \%$ ( $t$ test, $p<0.025$ ). Of the five animals in the group, the one with enlarged ventricles (case A3) was the most impaired on the performance test (see Fig. 9); nevertheless, elimination of this animal does not greatly alter the group's average performance score $(83 \%$ excluding case A3 as compared with the $80 \%$ including it). Not only was there an overall difference in the performance of the amygdalectomized and hippocampectomized groups, but also their performance curves showed a significant interaction even when the scores of the animals with combined lesions were eliminated $(F(3,21)$ $=4.37, p<0.025$ ). The interaction was manifested as a progressive decline in the scores of the amygdalectomized monkeys relative to the hippocampectomized monkeys with the progressively longer delays (see Fig. 8), although it is of interest that the amygdalectomized monkey with inferior frontal damage (case A4) failed to show this decline.

Combined removals. The group with combined ablation of the amygdaloid complex and hippocampal formation was the most severely impaired in relearning the tactual memory task. Only one animal in three reattained the criterion with single sample presentation, and this one (AH2) required the full 1000 trials despite having had two-stage surgery, training before each stage, and sparing of the posterodorsal part of the amygdala bilaterally. All three of these factors could have contributed to the animal's relatively successful relearning, since the other two animals, AH1 and AH3, who had none of these advantages, had to be given double sample presentation and still achieved only $84 \%$ and $77 \%$ correct responses, respectively, over the additional 500-trial training period. The retraining given this group was significantly greater than that required not only by the hippocampectomized group (Mann-Whitney $U$ test, $U=0, p=0.028$ ) but also by the amygdalectomized group $(U=1.5, p=0.054)$. Although two of the three animals with combined lesions did not reattain criterion, the group averaged $84 \%$ correct responses at the 10 -sec delay. With the imposition of longer delays, all three animals, including the two that continued to receive double sample presentation, showed extremely rapid forgetting (Fig. 8). Whereas the combined lesion group, like the others, had averaged about $91 \%$ correct responses over the three longest delays preoperatively, postoperatively it averaged only $63 \%$. This latter score differed significantly not only from the group's preoperative score $(t$ test, $p<0.02$ ) but also from the postoperative scores of both of the other groups (Newman-Keuls test, $p<0.01$, for both AH versus $\mathrm{H}$ and $\mathrm{AH}$ versus $\mathrm{A})$. The combined lesion group's sharp decline in scores on the performance test clearly contributed substantially to the overall interaction between group and delay.

Correlation between relearning and performance. Figure 10 shows each animal's postoperative performance score (average percentage of correct responses for the three longer delays) plotted as a function of its postoperative relearning score (number of trials to reattain criterion on the basic tactual memory task). The correlation between postoperative relearning and performance is large and highly significant $(r=-0.84, n=12$, $p<0.001$ ) and is even greater if the hydrocephalic case (A3) is excluded $(r=-0.92, n=11, p<0.001)$. By contrast, neither postoperative measure was significantly correlated with any preoperative score. This pattern of results strongly implies that a single factor acting postoperatively underlies both the relearning and performance deficits of the affected animals, an implication that is examined further under "Discussion."

Analysis of stimulus comparisons. As indicated earlier, a record was kept for each test trial of whether the animal touched both stimuli before making a choice. All but three animals (A4, AH1, and AH3) started making comparisons immediately upon postoperative testing, and the three exceptions did so within 300 trials. On average, the animals were found to compare stimuli on about $60 \%$ of their relearning trials and no group differences were evident. On the performance test, however, on which the animals compared stimuli on approximately $64 \%$ of the trials, the amygdalectomized monkeys were found to compare stimuli more often than those in the other groups, although only the difference with the combined lesion group attained significance (A versus $\mathrm{AH}, U=0$, 
TABLE I

Scores on DNMS in the dark ${ }^{a}$

\begin{tabular}{|c|c|c|c|c|c|c|c|c|c|c|c|}
\hline \multirow[b]{2}{*}{ Group } & \multicolumn{5}{|c|}{ PRE-OP } & \multicolumn{6}{|c|}{ POST-OP } \\
\hline & $10 \mathrm{sec}$ & $30 \mathrm{sec}$ & $60 \mathrm{sec}$ & $120 \mathrm{sec}$ & $\overline{\mathrm{X}}^{b}$ & $\begin{array}{l}\text { Trials to } \\
\text { Relearn }\end{array}$ & $10 \mathrm{sec}$ & $30 \mathrm{sec}$ & $60 \mathrm{sec}$ & $120 \mathrm{sec}$ & $\overline{\mathrm{x}}$ \\
\hline \multicolumn{12}{|l|}{ Hippocampectomy } \\
\hline H1 & 94 & 94 & 88 & 91 & 91.0 & 0 & 92 & 91 & 94 & 92 & 92.3 \\
\hline $\mathrm{H} 2$ & 94 & 89 & 88 & 89 & 88.8 & 40 & 91 & 93 & 94 & 88 & 91.6 \\
\hline H3 & 96 & 93 & 91 & 90 & 91.3 & 40 & 94 & 98 & 98 & 94 & 96.6 \\
\hline $\mathrm{H} 4$ & 94 & 95 & 95 & 93 & 94.3 & 0 & 91 & 95 & 95 & 95 & 95.0 \\
\hline \multicolumn{12}{|l|}{ Amygdalectomy } \\
\hline $\mathrm{A} 1$ & 92 & 90 & 87 & 91 & 89.3 & $1020^{c}$ & 90 & 86 & 80 & 78 & 81.3 \\
\hline $\mathrm{A} 2$ & 98 & 97 & 94 & 94 & 95.0 & 340 & 90 & 90 & 87 & 86 & 87.6 \\
\hline A3 & 93 & 88 & 86 & 87 & 87.0 & 440 & 91 & 76 & 66 & 62 & 68.0 \\
\hline A4 & 91 & 95 & 93 & 97 & 95.0 & $1000 \mathrm{~F}^{d}$ & 81 & 80 & 82 & 81 & 81.0 \\
\hline A5 & 92 & 91 & 90 & 91 & 90.7 & 780 & 90 & 88 & 83 & 77 & 82.6 \\
\hline \multicolumn{12}{|c|}{$\begin{array}{l}\text { Amygdalectomy + hippocam- } \\
\text { pectomy }\end{array}$} \\
\hline AH1 & 94 & 89 & 94 & 91 & 91.3 & $1500 \mathrm{~F}^{c}$ & 84 & 68 & 60 & 58 & 62.0 \\
\hline $\mathrm{AH} 2$ & \multicolumn{5}{|c|}{ two-stage surgery } & 1000 & 90 & 70 & 67 & 54 & 63.6 \\
\hline AH3 & 91 & 92 & 94 & 88 & 91.3 & $1500 \mathrm{~F}^{c}$ & 77 & 66 & 56 & 68 & 63.3 \\
\hline
\end{tabular}

"Scores are percentages correct in 100 trials except for those listed under " $\overline{\mathrm{X}}$ " and "Trials to Relearn."

${ }^{b}$ Mean percentage correct on performance test (i.e., average score for the three longest delays).

${ }^{c}$ Double presentation of sample, instituted after 1000 trials of relearning and continued throughout the performance test.

${ }^{d} \mathrm{~F}$, failed to relearn in the number of trials indicated.

$p=0.018)$. There were no significant differences in the number of comparisons as a function of delay, nor was there any interaction between group and delay, suggesting that all groups attempted a tactile solution even at the longest interval.

Analysis of errors. On average, animals made approximately half of their relearning errors by displacing the incorrect object directly (i.e., on "noncomparison" trials) and the other half by displacing the incorrect object following comparison with the correct object. Although the amygdalectomized monkeys tended to make more than half of their errors on comparison trials, reflecting their greater frequency of comparisons, there were no group differences on the error measure. On the performance test, whereas animals with hippocampectomy alone and combined lesions continued to make about half their errors on comparison trials, animals with amygdalectomy committed $68 \%$ of their errors on comparison trials and were found to differ significantly from animals with combined lesions on this measure (A versus AH, $U=1, p=0.036$ ). Again, no other group comparisons were significant. Neither in relearning nor on the performance test were there group differences in the number of errors made to specific objects or places. Indeed, there was little evidence that any animal made a preponderant number of errors due to responding to a particular object or to a particular side of the test tray either within or across days. Group differences did emerge, however, in the number of correction trials per error (correction ratio). Thus, in the first 300 postoperative trials the hippocampectomized monkeys had correction ratios ranging from 1.0 to 1.2 , which were significantly less than those of both the amygdalectomized monkeys, with ratios ranging from 1.2 to $1.6(\mathrm{H}$ versus $\mathrm{A}, U=1.4, \mathrm{p}<0.05$ ), and the animals with combined lesions, with ratios ranging from 1.5 to 1.7 ( $\mathrm{H}$ versus $\mathrm{AH}, U=0, p=0.028$ ). The difference between the latter two groups fell short of significance (A versus $\mathrm{AH}, U=2, p=0.071$ ). The elevated correction ratios in the amygdalectomized and combined lesion groups are probably not a reflection of perseverative tendencies, since, as already indicated, these animals failed to show clear object or place preferences. It seems more likely that the elevated ratios simply reflect their poor memory.

\section{Visual DNMS}

With one exception, all monkeys transferred perfectly from tactual DNMS (120-sec delays) to visual DNMS (10-sec delays) on the same set (small set A). 'I'he exception, case AH3, had to be retrained in the light, first for 1000 trials with single sample presentations and then for 100 additional trials with double sample presentations, before it reattained criterion. Even then, when returned to single sample presentations, it achieved a stable score of only $75 \%$ correct responses at the 10 -sec delay interval.

As shown in Figure 11 and Table II, the monkeys' scores on the visual version of the memory task were, in general, higher than they had been on the tactual version. Nevertheless, imposition of the longer delays revealed a pattern of forgetting

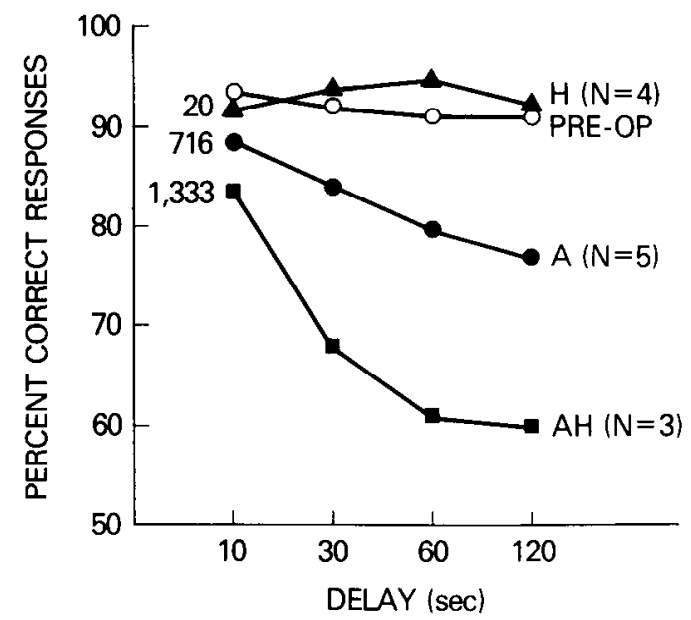

Figure 8. Tactual DNMS, group averages. The preoperative curve $(P R E-O P)$ shows the average scores for 11 animals. One animal that originally received a hippocampectomy later received an amygdalectomy as well; therefore, this animal is included in two different lesion groups ( $H$ and $A H)$. To the left of each curve is the average number of trials that that group required to relearn tactual DNMS. 


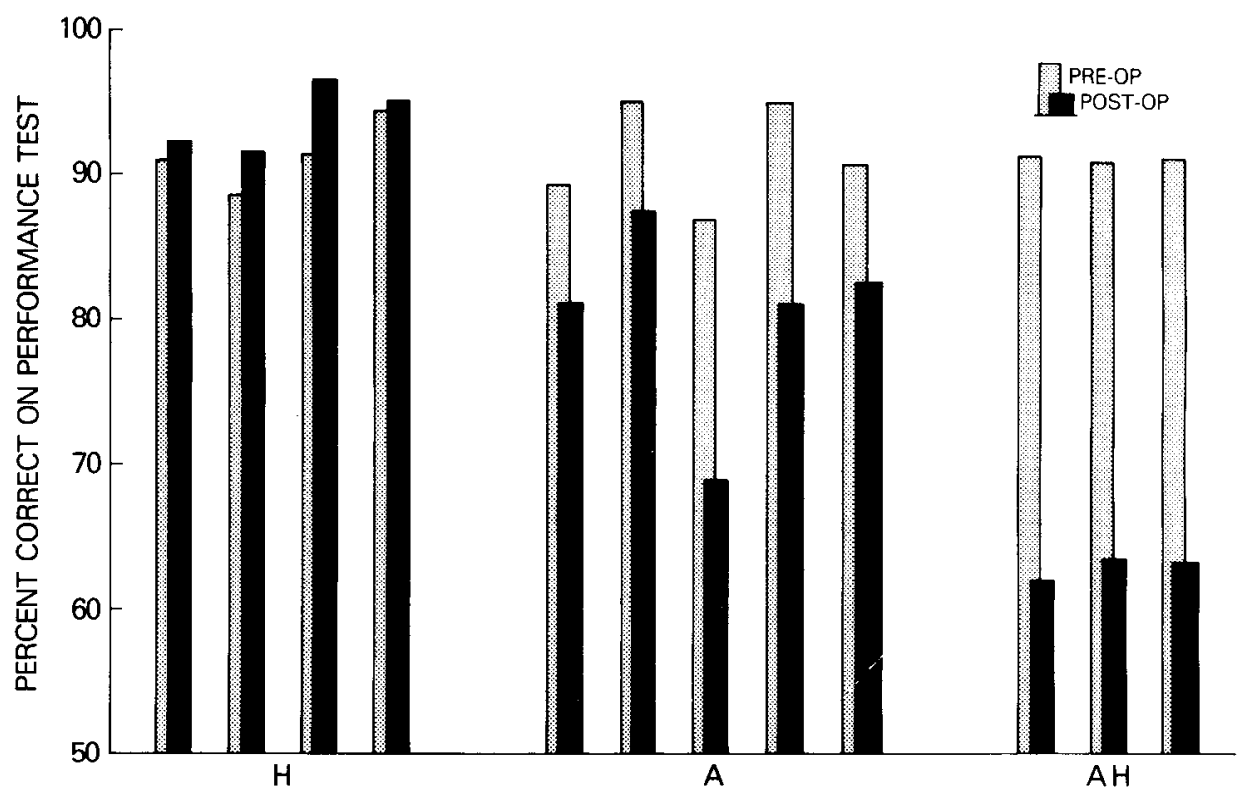

Figure 9. Tactual DNMS, individual performance. Each pair of bars represents a single animal's preoperative and postoperative scores averaged over the three longer delays. The animals within a group are arranged in order of case numbers from left to right ( $\mathrm{H} 1$ to $\mathrm{H} 4, \mathrm{~A} 1$ to $\mathrm{A} 5$, and $\mathrm{AH} 1$ to $\mathrm{AH} 3$ ). Case $\mathrm{A} 3$ is the monkey with hydrocephalus.

across lesion groups that was highly similar to the pattern displayed earlier in tactual DNMS. This is reflected in an interaction of group and delay that approached significance $(F$ (estimated $d f 2.42,8.49)=4.07, p<0.06)$. As before, the hippocampectomized monkeys displayed a high level of performance at all delays, whereas the monkeys with combined lesions, while performing well above chance with short delays, were close to chance at the longer delays. Again, just as in touch, the group with amygdaloid lesions performed at a level between the other two groups, i.e., more poorly than those with hippocampal ablations but better than those with combined lesions. Interestingly, the hydrocephalic monkey (case A3), which had the lowest performance score of the amygdalectomized group on the tactile task and whose behavior on this measure approached that of the animals with combined lesions (see Table I and Fig. 9), had a performance score on the visual task that fell midway among the scores of the amygdalectomized group (see Table II). Although the reason for this pattern of scores is unclear, it is tempting to speculate that in this animal, whose hydrocephalus presumably was long-standing, visual memory developed at the expense of tactual memory.

Effect of set size on performance. The results on visual DNMS with the three different stimulus sets are presented in Table II. When tested with a set of 40 objects, the amygdalectomized monkeys were found to perform significantly more poorly than animals with hippocampal ablations at the 60 - and 120 -sec delays on small set A ( $t$ test, $p<0.05, p<0.057$, respectively) and at the 120 sec delays on small set $B(t$ test, $p<0.05)$. The two groups did not differ, however, when tested with a larger pool of 200 objects. The relation between performance and set size is illustrated in Figure 12.

\section{Discussion}

\section{Effects of combined ablations of the amygdaloid complex and hippocampal formation}

The present results corroborate the initial demonstration (Mishkin, 1978) that combined damage to the amygdaloid complex and hippocampal formation in monkeys produces a far more severe sensory memory deficit than is produced by

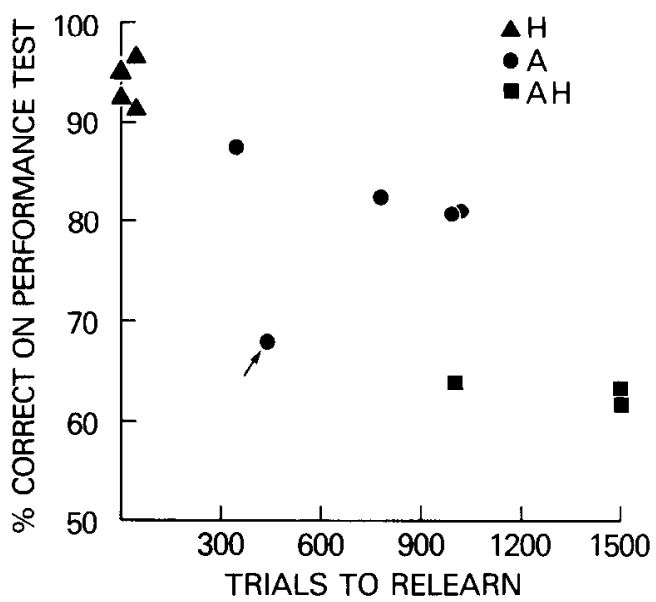

Figure 10. Correlation of tactual relearning and performance scores. The number of trials each animal required to relearn tactual DNMS with a 10-sec delay (postoperatively) is plotted against its average postoperative score on the three longer delays. The two measures are significantly correlated $(r=-0.84, n=12, p<0.001)$. The arrow indicates case A3, the animal with hydrocephalus; removal of this animal yields a higher correlation $(r=-0.92, n=11, p<0.001)$.

damage to either structure alone. More importantly, these results extend the earlier findings by showing that the foregoing conclusion applies to tactual as well as to visual memory. Indeed, the impairment in touch after combined lesions appears to be even more severe than the impairment found originally in vision. A possible explanation for this difference is discussed below in connection with the effects of amygdalectomy.

The finding of a bimodal impairment after limbic lesions is not new. It had already been shown not only that animals with combined lesions (Deuel and Mishkin, 1977) but also those with hippocampectomy alone (Moss et al., 1981) and amygdalectomy alone (Schwartzbaum and Poulos, 1965) are impaired on certain discrimination learning and reversal tasks in both the visual and tactual modalities. The present study, however, by demonstrating a significant interaction between group and 
delay, suggests in addition that this bimodal impairment after limbic lesions is mnemonic.

\section{Effects of amygdalectomy}

In the present experiment, unlike the earlier study (Mishkin, 1978), amygdalectomy produced a greater memory impairment than did hippocampectomy, a difference that was evident in both the tactual and visual versions of the test. The discrepancy probably reflects the different set sizes that were employed in the two experiments. Evidence for this proposal is provided by the finding that, within the present experiment, amygdalectomized monkeys were moderately impaired relative to hippocampectomized monkeys when tested with a set of 40 objects but not when tested with a set of 200 objects. Further support comes from studies (Correll and Scoville, 1965; Mishkin and Oubre, 1976) demonstrating that amygdalectomized but not hippocampectomized monkeys are markedly impaired on visual delayed matching- or nonmatching-to-sample when only one pair of stimuli is used repeatedly, the classical method of testing visual memory. In short, the memory deficit after amygdalectomy appears to be inversely related to the size of the stimulus set. Such a relationship suggests that the underlying impairment is not simply in recognition, i.e., the ability to distinguish a novel from a previously presented stimulus; rather, the im- pairment would seem to be in recency memory, i.e., the ability to distinguish between two familiar stimuli on the basis that one was experienced more recently than the other. The alternative possibility, namely, that the basic impairment is in associating the characteristic of recency with the reward (a form of associative memory), appears to be ruled out by the finding that the amygdalectomized monkeys were impaired at long delays even after they had mastered the associative rule at short delays. This consideration leads, in turn, to the conclusion that the common factor underlying the high correlation between postoperative relearning and performance among the animals of the present study is their recency-memory ability. In short, the poorer this memory ability as measured by the performance test, the slower the postoperative relearning of the associative rule, since recency memory is clearly essential for acquisition of the rule. Furthermore, an impairment in recency memory could well be exacerbated in tactual as compared with visual DNMS because there are fewer characteristics that can be used to discriminate objects by touch than by vision, and, hence, there should be an apparently greater stimulus repetition and concomitantly greater dependence on the quality of recency in touch than in vision.

The foregoing analysis must apply also to the impairment of animals with combined limbic lesions. Such monkeys, unlike those with amygdalectomy alone, were found earlier to be
Figure 11. Comparison of tactual DNMS $(A)$ and visual DNMS $(B)$ with the same object set (small set A). Curves in $A$ differ slightly from those in Figure 8 , the former being based only on those animals subsequently tested on visual DNMS: $\mathrm{H}(N=3) ; \mathrm{A}(N=5) ; \mathrm{AH}(N=$ 2).
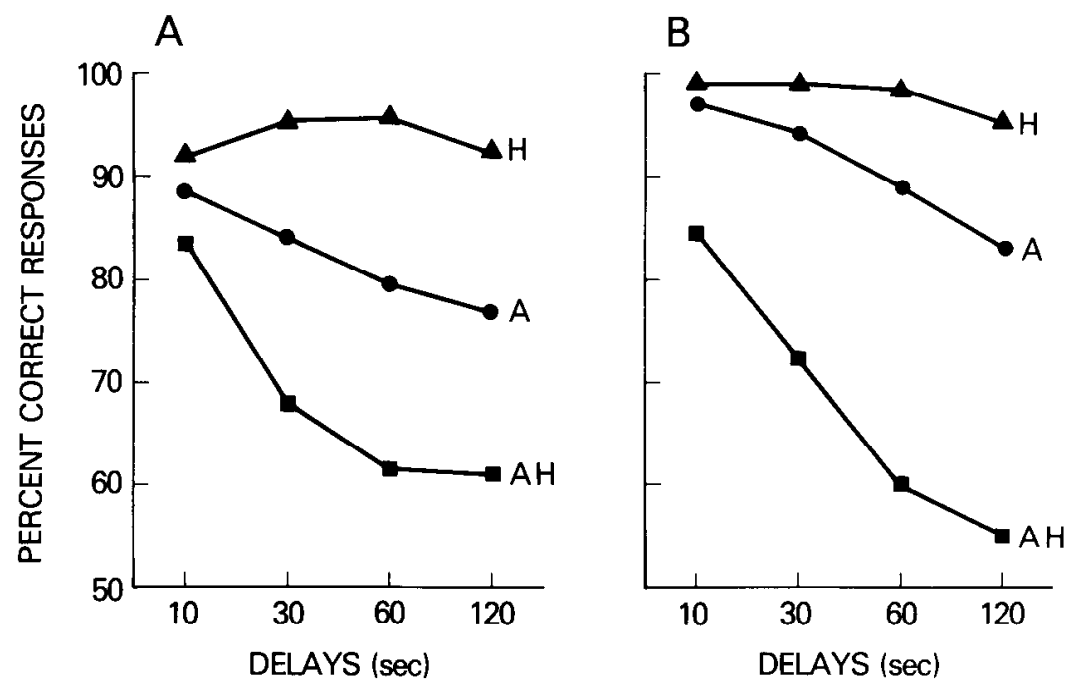

TABLE II

Scores on DNMS in the light ${ }^{a}$

\begin{tabular}{|c|c|c|c|c|c|c|c|c|c|c|c|c|c|c|c|}
\hline \multirow{2}{*}{ Group } & \multicolumn{5}{|c|}{ Small Set A } & \multicolumn{5}{|c|}{ Large Set } & \multicolumn{5}{|c|}{ Small Set B } \\
\hline & $10 \mathrm{sec}$ & $30 \mathrm{sec}$ & $60 \mathrm{sec}$ & $120 \mathrm{sec}$ & $\overline{\mathrm{X}}^{b}$ & $10 \mathrm{sec}$ & $30 \mathrm{sec}$ & $60 \mathrm{sec}$ & $120 \mathrm{sec}$ & $\overline{\mathrm{X}}$ & $10 \mathrm{sec}$ & $30 \mathrm{sec}$ & $60 \mathrm{sec}$ & $120 \mathrm{sec}$ & $\overline{\mathrm{X}}$ \\
\hline \multicolumn{16}{|l|}{ Hippocampectomy } \\
\hline $\mathbf{H} 2$ & 99 & 99 & 96 & 92 & 95.7 & 99 & 100 & 97 & 98 & 98.3 & 100 & 98 & 92 & 93 & 94.3 \\
\hline H3 & 100 & 100 & 100 & 97 & 99.0 & 100 & 100 & 98 & 97 & 98.3 & 100 & 100 & 100 & 96 & 98.7 \\
\hline $\mathrm{H} 4$ & 99 & 100 & 100 & 96 & 98.7 & 99 & 98 & 100 & 98 & 98.7 & 99 & 100 & 99 & 100 & 99.7 \\
\hline \multicolumn{16}{|l|}{ Amygdalectomy } \\
\hline A1 & 96 & 90 & 86 & 75 & 83.7 & 100 & 98 & 99 & 93 & 96.7 & 100 & 94 & 93 & 87 & 91.3 \\
\hline $\mathrm{A} 2$ & 100 & 99 & 97 & 93 & 96.3 & 100 & 99 & 99 & 96 & 98.0 & 100 & 98 & 97 & 93 & 96.0 \\
\hline A3 & 96 & 97 & 91 & 83 & 90.3 & 100 & 100 & 97 & 97 & 98.0 & 100 & 98 & 98 & 92 & 96.0 \\
\hline A4 & 99 & 95 & 87 & 85 & 89.0 & 99 & 99 & 99 & 98 & 98.7 & 99 & 94 & 94 & 91 & 93.0 \\
\hline \multicolumn{16}{|c|}{$\begin{array}{l}\text { Amygdalectomy + hippocam- } \\
\text { pectomy }\end{array}$} \\
\hline $\mathrm{AH} 2$ & 94 & 82 & 58 & 50 & 63.3 & & & & & & & & & & \\
\hline AH3 & 75 & 63 & 62 & 60 & 61.7 & & & & & & & & & & \\
\hline
\end{tabular}

${ }^{a}$ Scores are percentages correct in 100 trials, except for those under " $\overline{\mathrm{X}}$. "

${ }^{b}$ Mean percentage correct on performance test (i.e., average score for the three longest delays). 


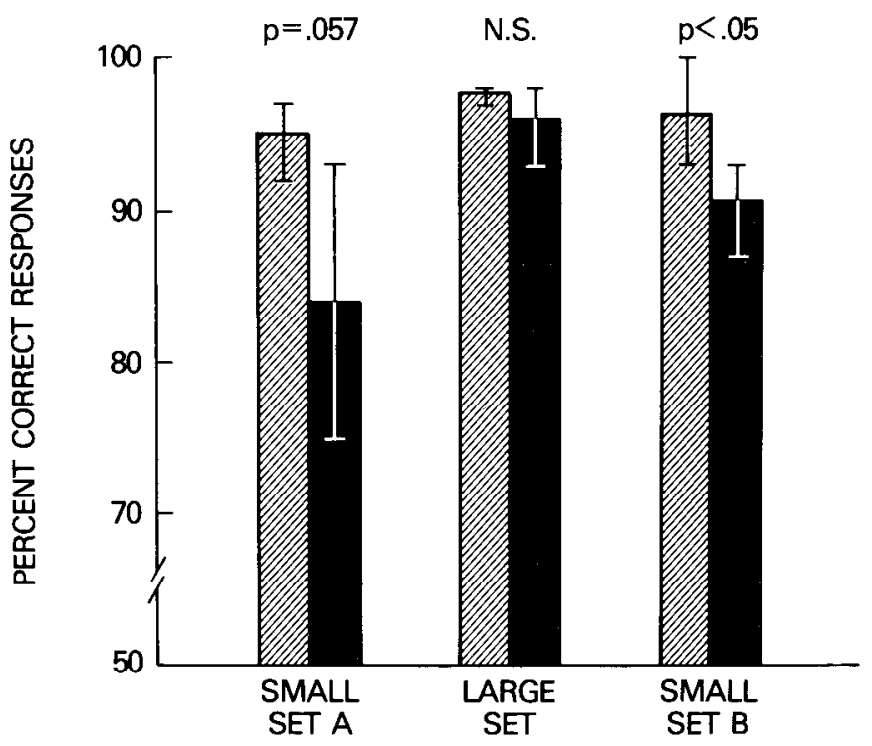

Figure 12. Effect of size of object set on performance of visual DNMS at a delay of $120 \mathrm{sec}$. Black bars indicate scores of amygdalectomized monkeys (cases A1 to A4), and bars with oblique hatching indicate scores of hippocampectomized monkeys (cases $\mathrm{H} 2$ to $\mathrm{H} 4$ ). Vertical lines indicate ranges of scores. Small sets $A$ and $B$ consisted of 40 objects cach; large set consisted of 200 objects. Histograms cxclude scores for case A5 since this animal was tested on small set A only. If this animal's score on small set $A$ is included, the difference between groups $\mathrm{A}$ and $\mathrm{H}$ is significant at the 0.036 level.

impaired in the basic process of recognition memory ( $\bar{M}$ Mishkin, 1978), and presumably this is the primary reason for their impairment in the present study as well. In addition, however, the use of a small pool of objects in the present study and the consequent demand on recency as well as recognition memory may have exacerbated their deficit. This possibility is consistent with the finding that the two animals with combined lesions that were tested on visual DNMS in the present study performed worse, on average, than those in the earlier study, despite an incomplete lesion in one of the present animals (AH2).

\section{Effects of hippocampectomy}

The hippocampectomized animals performed at high levels throughout the experiment on both the tactual and visual versions of DNMS; indeed, since they were near ceiling performance, their scores probably could not have been exceeded by those of unoperated animals. These results contrast with those of previous experiments on sensory memory in vision in which hippocampectomized monkeys were found to be at least mildly (Mishkin, 1978) to moderately (Mahut et al., 1982) impaired. Since there were numerous procedural differences between the previous and present experiments, there are many possible explanations for the differences in results, none of which logically excludes any other. For example, whereas the two previous experiments used rhesus monkeys ( $M$. mulatta), the present one employed cynomolgus monkeys $(M$. fascicularis), and a contribution from this species difference cannot be ruled out. But there are other, perhaps more likely, possibilities. For example, differences in the amount of preoperative training may have contributed to the differences in results (see Mahut et al., 1982). Of the two previous experiments, the one employing no preoperative training on the basic task (Mahut et al., 1982) yielded a greater impairment than the one that did employ such training (Mishkin, 1978). Since the present experiment, in which there appeared to be no impairment, involved even more preoperative training, the three experi- ments taken together suggest that there may be a direct correlation between the amount of preoperative training and the level of post-hippocampectomy performance. Support for this idea is provided by a second set of experiments, which examined the effects of fornix transection on visual memory in monkeys. Here, also, there was a difference in results across studies, with animals that received no preoperative training (Gaffan, 1974) again showing greater impairment than those that did (Bachevalier et al., 1982).

Still another possible explanation for the good performance of the hippocampectomized monkeys in the present study relates to the size of the stimulus set. That is, whereas the small size of the set used to test tactual and visual memory in the present study appeared to be detrimental for the amygdalectomized monkeys, it may paradoxically have helped the hippocampectomized animals. This possibility is raised by the results of an experiment in which animals were trained on a series of DNMS tasks that progressed from one that employed trial-unique stimuli, through an intermediate stage, to one that made use of a single pair of stimuli presented repeatedly (Mishkin and Delacour, 1975). Under these conditions, hippocampectomized monkeys learned DNMS with the single pair of repeatedly used stimuli significantly faster even than unoperated control monkeys (M. Mishkin and J. L. Oubre, unpublished data). No firm conclusion can be drawn with regard to the specific contribution of set size to the performance of the hippocampectomized monkeys in the present study, since their performance was at or near ceiling during this phase of the testing.

\section{Neuroanatomy of amnesia}

Although the present data appear to provide strong support for the argument that combined ablation of the amygdala and hippocampus is necessary to produce a severe sensory memory deficit, there are several alternative explanations for the findings that need to be considered.

Inferior temporal cortex. This tissue, which is adjacent to the temporal lobe limbic structures, is known to be important for visual perception and memory (Fuster et al., 1981; Mishkin, 1982), and it is therefore reasonable to suppose that unintended damage to this region or to the subjacent white matter (Horel, 1978; Horel and Pytko, 1982) could be responsible for the visual memory deficit being attributed here to limbic damage. However, even if it held for the visual memory deficit, this explanation is unlikely to apply to the associated deficit in tactual memory, since extensive bilateral ablation of inferior temporal cortex produces no discernible tactile impairment (Wilson, 1957; Moss et al., 1981). But the foregoing explanation, in fact, does not apply even to vision. First, it was found recently that temporal stem damage by itself does not produce visual memory deficits (Zola-Morgan et al., 1982). Second, in the present study, the inferior temporal damage in the animals with hippocampectomy alone, who were unimpaired in vision, was just as great as in the animals with combined lesions, who were profoundly impaired.

Even though the unintended inferior temporal damage cannot account for the impairment after the combined limbic lesions, it had been anticipated that the occurrence of such damage, particularly in the animals with hippocampectomy alone, would be accompanied by some impairment in visual memory. Yet, there was no apparent correlation hetween the hippocampectomized animals' level of performance and the extent of their inferior temporal cortical damage. In particular, the animal with almost complete unilateral destruction of the inferior temporal cortex, case $\mathrm{H} 4$, performed at least as well as the others on the visual memory tasks, whereas the lowestscoring animal, case $\mathrm{H} 2$, had only moderate unilateral damage to this cortex. The lack of correlation may not be surprising, 
since the unintended damage was mainly unilateral. Nevertheless, there may be a hidden correlation. The unintended inferior temporal damage in case $\mathrm{H} 2$ was on the side opposite the hand used in testing, whereas in case $\mathrm{H} 4$ it was on the side ipsilateral to the tested hand. Although tactual training restricted to one hand (Ebner and Myers, 1962) or visual training restricted to one hemifield (Hamilton, 1976) has been shown to result in the storage of information in both hemispheres, the trace strength in the two may not be equivalent (cf. Ebner and Myers, 1962; Semmes and Mishkin, 1965). That is, there may be an asymmetrical engagement of the hemispheres in visual memory that is dependent on the performing hand, particularly when it has been preceeded by testing of tactual memory through this same hand. Such a functional asymmetry could explain why case $\mathrm{H} 2$, with the lesser amount of unilateral inferior temporal damage but with this damage occurring in a more critical hemisphere, performed more poorly than case $\mathrm{H} 4$. Although such an explanation is of course speculative, it is one that can be tested experimentally.

Hippocampus. The evidence that a limbic lesion produces severe memory deficits only if both the amygdala and hippocampus are damaged in combination has recently been reinterpreted in a way that still attributes memory processes to the hippocampus alone (Squire and Zola-Morgan, 1983). This reinterpretation is based on the argument that, because of its relative inaccessibility, the rostral pole of the hippocampus could well remain intact in some animals with putatively complete hippocampal removals but would always be removed when the rostrally adjacent amygdala was ablated in addition. Thus, a severe impairment is produced only by the combined ablation because only this lesion leads to complete removal of the hippocampal formation. In the present study, however, all of the animals with hippocampectomy alone had removals that were verified to be complete anteriorly (see "Histology"), and yet none appeared to be impaired on either the tactual or visual tasks. This evidence is inconsistent with the proposal that, of the medial temporal structures, the hippocampal formation alone is responsible for the formation of new memories.

Amygdalohippocampal area. Another anatomical region that might sustain damage only when the amygdala and hippocampus are removed in combination and that could thus be responsible for the severe memory deficit that follows medial temporal surgery is the amygdalohippocampal area (AHA). The AHA lies on the medial surface of the temporal lobe between the amygdala and hippocampus and forms a transition zone between the cortical nucleus of the amygdala and the hippocampus (Berman and Jones, 1982). In fact, however, no animal was found to have complete bilateral removal of the AHA, and there was no relation between performance and partial damage to this area. For example, the least impaired animal with the combined lesion had a unilateral removal of the AHA, whereas the most impaired animal in this group appeared to have complete sparing of the region. Consequently, it appears highly unlikely that the AHA alone is critical for memory processes.

Entorhinal cortex. Still another region that must be considered is the entorhinal cortex, a periallocortical area intimately related to, and often considered to be part of, the hippocampal formation. This region, unlike the AHA, does qualify as a potential target of combined as opposed to separate lesions of the amygdala and hippocampus. That is, whereas amygdalectomy alone involved approximately the rostral one-third of the entorhinal cortex and hippocampectomy alone involved approximately the caudal one-third of the entorhinal cortex, combined ablations of the amygdala and hippocampus destroyed all of it. Since the entorhinal cortex has neuroanatomical connections with regions that have been implicated in memory processes (e.g., magnocellular division of the mediodorsal nucleus of the thalamus; Aggleton and Mishkin, 1984) and that are outside the target area of the subicular complex
(Rosene and Van Hoesen, 1977), it is possible that the combined limbic lesions are the most disruptive because of the accompanying destruction of entorhinal cortex. This possibility is strengthened by the recent observation that monkeys with entorhinal lesions alone are impaired on tests of concurrent visual discrimination learning (Moss et al., 1981). Analysis of the results of the present experiment, however, failed to reveal any within-group correlation between postoperative performance and extent of damage to entorhinal cortex. Because this negative outcome may have been due simply to the small variability in extent of damage to this region, a separate study was recently undertaken to investigate the role of the entorhinal cortex directly (Murray and Mishkin, 1983b). The results indicate that even removal of the entire entorhinal area together with the hippocampal formation fails to produce a severe visual recognition memory deficit in monkeys.

Hippocampus plus amygdala. The weight of the evidence thus suggests that it is indeed the combined ablation of amygdaloid complex and hippocampal formation that is responsible for the severe tactual and visual memory deficits that were observed in the present study. By implication, the present evidence also suggests that it is this combined damage that is responsible for the global amnesia observed in humans following medial temporal lobe surgery. But while a contribution from the hippocampus to memory is widely accepted, a contribution from the amygdala is not, perhaps because the amygdala has long been known to be essential for the generation of situationally appropriate motivational and affective states and, consequently, a critical role in memory processes by the same structure would appear to have been excluded. It is of interest in this connection that the animal with combined lesions that spared the posterodorsal amygdala (case AH2) showed none of the changes in emotional behavior that usually follow amygdalectomy; that is, this animal continued to be fearful of human observers and continued to be discriminating in its manual and oral inspection of objects. Nonetheless, this monkey was severely impaired in tests of both tactual and visual memory. The finding thus suggests that the affective/motivational functions of the amygdaloid complex may be at least partially separable from its memory functions. Such a possibility deserves careful study, for a functional dissociation offers one way to resolve the theoretical difficulty that is posed by postulating two major but disparate functions for this single structure (Mishkin and Aggleton, 1981).

\section{Sensory memories and corticolimbic pathways}

The present results have demonstrated that the amygdaloid complex and hippocampal formation are involved in both tactual and visual memory. It has recently been demonstrated that visual memory depends on an interaction between the cortical visual system, including the striate, prestriate, and inferior temporal cortex, and the limbic structures of the temporal lobe (Mishkin, 1982). By analogy, it has been proposed that tactual memory may also depend on interaction between a cortical sensory processing system and the temporal lobe limbic structures (Mishkin, 1979; Murray and Mishkin, 1984). The cortical processing system for touch may include the second somatosensory area (SII) and large portions of the insular cortex, since projections have been demonstrated from SII to the insula and from the insula directly to the amygdaloid complex and indirectly to the hippocampal formation via the perirhinal cortex (Mufson et al., 1981; Friedman et al., 1982; Mufson and Mesulam, 1982). Although the function of this pathway is still unknown, a tactual memory function for the limbic portion of the pathway is now clear. Thus, the possibility that the limbic structures participate in tactual memory on the basis of input they receive from the tactual cortical areas earlier in the pathway can now be tested experimentally. 


\section{References}

Aggleton, J. P., and M. Mishkin (1984) Projections of the amygdala to the thalamus in the cynomolgus monkey. J. Comp. Neurol. 222: 5668.

Bachevalier, J., J. K. Parkinson, J. P. Aggleton, and M. Mishkin (1982) Severe recognition impairment after combined but not separate transection of the amygdalofugal pathways. Soc. Neurosci. Abstr. 8: 23.

Berman, A. L., and E. G. Jones (1982) The Thalamus and Basal Telencephalon of the Cat, University of Wisconsin Press, Madison, WI.

Corkin, S. (1965) Tactually-guided maze learning in man: Effects of unilateral cortical excisions and bilateral hippocampal lesions. Neuropsychologia 3: 339-351.

Correll, R. E., and W. B. Scoville (1965) Performance on delayed match following lesions of medial temporal lobe structures. J. Comp. Physiol. Psychol. 60: 360-367.

Deuel, R. M., and M. Mishkin (1977) Limbic and prefrontal contributions to somesthetic learning in monkeys. Brain Res. 132: 521-535.

Fbner, F. F., and R. E. Myers (1962) Direct and transcallosal induction of touch memories in the monkey. Science 138: 51-52.

Friedman, D. P., E. A. Murray, and M. Mishkin (1982) Cortico-limbic pathway for touch: Connections via the somatosensory cortical fields in the lateral sulcus of the monkey. Soc. Neurosci. Abstr. 8: 38.

Fuster, J. M., R. H. Bauer, and J. P. Jervey (1981) Effects of cooling inferotemporal cortex on performance of visual memory tasks. Exp. Neurol. 71: 398-409.

Gaffan, D. (1974) Recognition impaired and association intact in the memory of monkeys after transection of the fornix. J. Comp. Physiol. Psychol. 86: 1100-1109.

Hamilton, C. R. (1976) Investigations of perceptual and mnemonic lateralization in monkeys. In Lateralization in the Nervous System, S. Harnad, ed., pp. 45-62, Academic Press, Inc., New York.

Horel, J. A. (1978) The neuroanatomy of amnesia. A critique of the hippocampal memory hypothesis. Brain 101: 403-445.

Horel, J. A., and D. E. Pytko (1982) Behavioral effect of local cooling in temporal lobe of monkeys. J. Neurophysiol. 47: 11-22.

Jarvis, M. J., and G. Ettlinger (1977) Cross-modal recognition in chimpanzees and monkeys. Neuropsychologia 15: 499-506.

Mahut, H., S. Zola-Morgan, and M. Moss (1982) IIippocampal resections impair associative learning and recognition memory in the monkey. J. Neurosci. 2: 1214-1229.

Miller, R. G. (1980) Simultaneous Statistical Inference, McGraw-Hill, New York.

Milner, B. (1972) Disorders of learning and memory after temporal lobe lesions in man. Clin. Neurosurg. 19: 421-446.

Mishkin, M. (1978) Memory in monkeys severely impaired by combined but not separate removal of amygdala and hippocampus. Nature 273 : $297-298$.

Mishkin, M. (1979) Analogous neural models for tactual and visual learning. Neuropsychologia 17: 139-151.

Mishkin, M. (1982) A memory system in the monkey. Philos. Trans. R. Soc. Lond. Biol. 298: 85-95.

Mishkin, M., and J. P. Aggleton (1981) Multiple functional contributions of the amygdala in the monkey. In The Amygdaloid Complex, Y. Ben-Ari, ed., pp. 409-420, Elsevier/North Holland Biomedical Press, Amsterdam.

Mishkin, M., and J. Delacour (1975) An analysis of short-term visual memory in the monkey. J. Exp. Psychol. 1: 326-334.

Mishkin, M., and J. L. Oubre (1976) Dissociation of deticits on visual memory tasks after inferior temporal and amygdala lesions in monkeys. Soc. Neurosci. Abstr. 2: 1127.
Mishkin, M., B. J. Spiegler, R. C. Saunders, and B. L. Malamut (1982) An animal model of global amnesia. In Alzheimer's Disease: A Report of Progress, S. Corkin, K. L. Davis, J. H. Growdon, E. Usdin, and R. J. Wurtman, eds., pp. 235-247, Raven Press, New York.

Moss, M., H. Mahut, and S. Zola-Morgan (1981) Concurrent discrimination learning of monkeys after hippocampal, entorhinal or fornix lesions. J. Neurosci. 1: 227-240.

Mufson, E. J., and M. -M. Mesulam (1982) Insula of the Old World monkey. II. Afferent cortical input and comments on the claustrum. J. Comp. Neurol. 212: 23-37.

Mufson, E. J., M. -M. Mesulam, and D. N. Pandya (1981) Insular interconnections with the amygdala in the rhesus monkey. Neuroscience 6: 1231-1248.

Murray, E. A., and M. Mishkin (1981) Role of the amygdala and hippocampus in tactual memory. Soc. Neurosci. Abstr. 7: 237.

Murray, E. A., and M. Mishkin (1983a) Severe tactual memory deficits in monkeys after combined removal of the amygdala and hippocampus. Brain Res. 270: 340-344.

Murray, E. A., and M. Mishkin (1983b) A further examination of the medial temporal-lobe structures involved in recognition memory in the monkey. Soc. Neurosci. Abstr. 9: 27.

Murray, E. A., and M. Mishkin (1984) Relative contributions of SII and area 5 to tactile discrimination in monkeys. Behav. Brain Res. 11: $67-83$

Penfield, W., and G. Mathieson (1974) Memory. Autopsy findings and comments on the role of the hippocampus in experiential recall. Arch. Neurol. 31: 145-154.

Penfield, W., and B. Milner (1958) Memory deficit produced by bilateral lesions in the hippocampal zone. Am. Med. Assoc. Arch. Neurol. Psychiatry 79: 475-497.

Rosene, D. L., and G. W. Van Hoesen (1977) Hippocampal efferents reach widespread areas of cerebral cortex and amygdala in the rhesus monkey. Science 198: 315-317.

Schwartzbaum, J. S., and D. A. Poulos (1965) Discrimination behavior after amygdalectomy in monkeys: Learning set and discrimination reversals. J. Comp. Physiol. Psychol. 60: 320-328.

Scoville, W. B., and B. Milner (1957) Loss of recent memory after bilateral hippocampal lesions. J. Neurol. Neurosurg. Psychiatry 20: 11-21.

Semmes, J., and M. Mishkin (1965) Somatosensory loss in monkeys after ipsilateral cortical ablation. J. Neurophysiol. 28: 473-486.

Siegel, S. (1956) Nonparametric Statistics for the Behavioral Sciences, McGraw-Hill, New York.

Squire, L. R., and S. Zola-Morgan (1983) The neurology of memory: The case for correspondence between the findings for human and nonhuman primate. In The Physiological Basis of Memory, Ed. 2, J. A. Deutsch, ed., pp. 199-268, Academic Press, Inc., New York.

Swanson, L. W., and W. M. Cowan (1975) Hippocampo-hypothalamic connections: Origin in subicular cortex, not in Ammon's Horn. Science 25: 303-304.

Weiskrantz, L. (1956) Behavioral changes associated with ablation of the amygdaloid complex in monkeys. J. Comp. Physiol. Psychol. 49: 381-391.

Wilson, M. (1957) Effects of circumscribed cortical lesions upon somesthetic and visual discrimination in the monkey. J. Comp. Physiol. Psychol. 50: 630-635.

Winer, B. J. (1971) Statistical Principles in Experimental Design, McGraw-Hill, New York.

Zeal, A. A., and A. L. Rhoton, Jr. (1978) Microsurgical anatomy of the posterior cerebral artery. J. Neurosurg. 48: 534-559.

Zola-Morgan, S., L. K. Squire, and M. Mishkin (1982) 'The neuroanatomy of amnesia: Amygdala-hippocampus versus temporal stem. Science 218: $1337-1339$. 